\title{
MODELO DE AVALIAÇÃO DE MATURIDADE DA INDÚSTRIA 4.0 - ESTUDO DE CASO EM UM CENTRO DE DISTRIBUIÇÃO DE MEDICAMENTOS NA BAIXADA FLUMINENSE/RJ
}

\section{INDUSTRY MATURITY ASSESSMENT MODEL 4.0 - CASE STUDY IN A DRUG DISTRIBUTION CENTER IN BAIXADA FLUMINENSE/RJ}

Jorge Luiz Machado¹, Mariana Gonçalves de Carvalho Wolff², Ariele Silva Moreira Rodrigues ${ }^{3}$, Denise Carvalho Takenaka ${ }^{4}$, Marcos Azevedo Benac ${ }^{5}$

Submetido: $17 / 02 / 2021$

Aprovado: 28/02/2021

\section{RESUMO}

O avanço e aplicação de tecnologias inovadoras e disruptivas nos espaços industriais, está delineando a quarta revolução industrial, ou Indústria 4.0. Dessa forma, o presente artigo apresenta um modelo de maturidade, elaborado por meio do estudo de caso, utilizando o método Delphi adaptado, para avaliar o nível de maturidade de um Centro de Distribuição de Medicamentos na Baixada Fluminense, Estado do Rio de Janeiro - Brasil. O objetivo principal é descrever as tecnologias habilitadoras e mapear o nível de maturidade da logística desse centro de distribuição, sobre a realidade instalada e o potencial da empresa no atendimento dos requisitos da Indústria 4.0. Para isso, utilizou-se a metodologia de desenvolvimento do modelo de Maturidade - German Academy of Science and Engineering (ACATECH), que se baseia em seis etapas: informatização, conectividade, visibilidade, transparência, previsibilidade e adaptabilidade. Apresenta-se ao final do processo um modelo dividido em oito dimensões, agrupadas em três aspectos: Tecnologia, Organização e Pessoas. A aplicação prática do modelo revelou que o nível de maturidade desta empresa ainda não está dentro das práticas e conceitos da Industria 4.0; entretanto, a empresa está no processo de digitalização uma vez que a informação é substituída por componentes e sistemas conectados. Constata-se, então, que a empresa está no nível 2 e precisa homogeneizar todos os processos em sua cadeia de valor, introduzindo o tema "Industria 4.0" nas pautas de planejamento, investimento em tecnologias habilitadoras em toda linha de produção e capacitação continua dos seus colaboradores.

PALAVRAS-CHAVE: Indústria 4.0. Tecnologias Habilitadoras. Modelo de maturidade.

\section{ABSTRACT}

The advance and application of innovative and disruptive technologies in industrial spaces, is outlining the fourth industrial revolution, or Industry 4.0. Thus, this article presents a maturity model,

\footnotetext{
1 Bacharel em Administração pela Universidade Federal Rural do Rio de Janeiro (UFRRJ). https://orcid.org/0000-0003-0898-4254 - luizmachado.jorge@gmail.com

2 Doutora, Mestre e Engenheira de Produção, todas pela Universidade Federal Fluminense (UFF). https://orcid.org/0000-0002-5465-4128 - carvalho.mariana@gmail.com

3 Mestranda em Desenvolvimento Regional e Sistemas Produtivos pelo Centro Federal de Educação Tecnológica Celso Suckow da Fonseca (CEFET/RJ) e Bacharel em Administração pela pela Universidade Federal Rural do Rio de Janeiro (UFRRJ). - https://orcid.org/0000-0002-7295-9240 rodrigues.ariele.sm@gmail.com

4 Mestre em Gestão e Estratégia de Negócios e Bacharel em Administração, ambas pela pela Universidade Federal Rural do Rio de Janeiro (UFRRJ). - https://orcid.org/0000-0002-6241-4255 - denisecarvalho@globo.com 5 Doutor em Ciências Ambientais e Florestais, Mestre em Gestão e Estratégia de Negócios e Bacharel em Administração, todas pela Universidade Federal Rural do Rio de Janeiro (UFRRJ). - https://orcid.org/0000-00029121-3479 - marcosbenac@gmail.com
} 


\title{
RECIMA21 - REVISTA CIENTÍFICA MULTIDISCIPLINAR
}

\author{
MODELO DE AVALIACÃO DE MATURIDADE DA INDÚSTRIA 4.0 - ESTUDO DE CASO \\ EM UM CENTRO DE DISTRIBUIČ̃̃O DE MEDICAMENTOS NA BAIXADA FLUMINENSE/RJ \\ Jorge Luiz Machado, Mariana Gonçalves de Carvalho Wolff, Ariele Silva Moreira Rodrigues, \\ Denise Carvalho Takenaka, Marcos Azevedo Benac
}

elaborated through a case study, using the adapted Delphi method, to assess the maturity level of a Drug Distribution Center in Baixada Fluminense, State of Rio de Janeiro - Brazil . The main objective is to describe the enabling technologies and map the level of maturity of the logistics of this distribution center, on the installed reality and the company's potential in meeting the requirements of Industry 4.0. For that, we used the maturity model development methodology - German Academy of Science and Engineering (ACATECH), which is based on six steps: computerization, connectivity, visibility, transparency, predictability and adaptability. At the end of the process, a model divided into eight dimensions is presented, grouped into three aspects: Technology, Organization and People. The practical application of the model revealed that the level of maturity of this company is not yet within the practices and concepts of Industry 4.0; however, the company is in the process of digitization since the information is replaced by connected components and systems. It appears, then, that the company is at level 2 and needs to homogenize all processes in its value chain, introducing the theme "Industry 4.0" in the planning guidelines, investment in enabling technologies in the entire production line and continuous training of its employees.

KEYWORDS: Industry 4.0. Enabling Technologies. Maturity model.

\section{INTRODUÇÃO}

A demanda pelo uso das novas tecnologias, na mídia, na educação, no entretenimento, na medicina, nas relações de trabalho tem nos mostrado o quanto investir em tecnologias disruptivas, em especial, os sistemas de manufatura e logística industriais (cadeia de valor), das organizações e empresas, é fundamental. Perante os recentes desenvolvimentos tecnológicos e diante de um panorama em que há uma procura cada vez maior por produtos personalizados, maior complexidade, maior qualidade e custos reduzidos; a ascensão de um novo modelo de indústria está sendo discutido em todo o mundo sob o tópico de Indústria 4.0 (HERMANN et al., 2016; SANTOS et al., 2018).

A evolução dos sistemas de manufatura e logística industriais, devido ao crescente aumento da necessidade de interoperabilidade e a conectividade da rede mundial, através dos avanços tecnológicos de hardwares e softwares, traz mudanças significativas nas cadeias produtivas dos mais diversos segmentos que busca atender à crescente demanda mundial por produtos e serviços e a competitividade internacional das cadeias de abastecimento.

Para Santos (2018) o conceito de indústria 4.0 está relacionado à interoperabilidade (capacidade de um sistema de se comunicar de forma clara com outro sistema, sendo estes semelhantes ou não), ou seja, abrange um conjunto de tecnologias que permitem produtos inteligentes integrados em um processo digital interligado, tornando o processo produtivo em logística, cada vez mais ágil, fácil e confiável, com menor margem de erro na utilização de recursos e matérias primas.

Schumacher, Erol e Sihn (2016) e Schuh et al. (2017), criaram métodos de Avaliação de maturidade industrial. Para Schuh et al. (2017) é o mapa para que as empresas estejam preparadas para alcançarem a revolução da Indústria 4.0. As empresas, para adquirir suas competências digitais, segundo esses estudos, sugerem-nas o emprego de modelos de maturidade conhecido como 


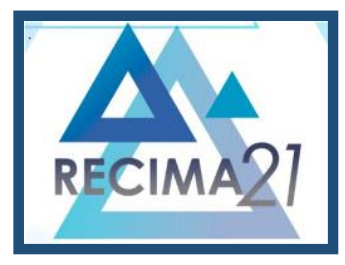

\section{RECIMA21 - REVISTA CIENTÍFICA MULTIDISCIPLINAR}

MODELO DE AVALIACÃO DE MATURIDADE DA INDÚSTRIA 4.0 - ESTUDO DE CASO EM UM CENTRO DE DISTRIBUIÇÃO DE MEDICAMENTOS NA BAIXADA FLUMINENSE/RJ Jorge Luiz Machado, Mariana Gonçalves de Carvalho Wolff, Ariele Silva Moreira Rodrigues, Denise Carvalho Takenaka, Marcos Azevedo Benac

ACATECH (German Academy of Science and Engineering - Academia Alemã de Ciências e Engenharia), foco do nosso estudo.

As empresas brasileiras, segundo dados levantados pela Confederação Nacional das Indústrias (CNI, 2015), têm baixos índices de produtividade, o que indica a desorganização do processo produtivo, requisito básico, para a aplicação dos conceitos de Indústria 4.0. Tal condição mostra que o país não está preparado para introduzir as tecnologias habilitadoras em seu parque industrial, essencial, para a interoperabilidade nos sistemas de manufatura e logística industriais e, consequentemente, evolução em maturidade da quarta revolução industrial (CIRERA; MALONEY, 2017; RIBEIRO, 2018).

Segundo Ribeiro (2018) e CNI (2015), este problema com a produção industrial, acrescentando a baixa qualificação do trabalho nas empresas, tem dificultado a competitividade da indústria nacional em âmbito mundial.

Diante do exposto, essa dificuldade apresentada pela indústria nacional, nos leva ao estudo de caso em uma empresa de distribuição de medicamentos, situada em um parque industrial da Baixada Fluminense. A finalidade é avaliar a maturidade dessa empresa frente ao cenário e conceito da Indústria 4.0. Para tanto, pretende-se propor uma adaptação de modelos de maturidade para localizar em qual nível de maturidade essa empresa está frente à transformação digital.

Transformação digital atrelada às tecnologias que habilitam a empresa a estar apta ao conceito de Indústria 4.0, baseia-se em pilares, como: Internet das Coisas (IoT), cloud computing, Inteligência Artificial (I.A) das máquinas (M2M), impressão 3D, Data mining (Mineração de dados), big data, cyber-physical systems (CPS), RFID, blockchain, realidade aumentada, realidade virtual, robôs, Internet das industrias (IIoT), AGV, ciber segurança e Rede $5 G$, serão conceituadas e a sua existência ou não na empresa serão analisadas.

Diante desse cenário, pretende-se responder a seguinte questão de pesquisa: Qual o nível de maturidade da indústria 4.0, para uma logística do futuro em um centro de distribuição de medicamentos da Baixada Fluminense? Ou seja, numa escala de um a cinco, em que nível do modelo a empresa se encontra. Para isso, o presente estudo, descreve um arcabouço conceitual, construído a partir da leitura e análise sistemática de pesquisas bibliográficas, visitas técnicas e a produção de um questionário, baseado no modelo Delphi e no teste online disponibilizado, em 2018, pelo SENAI 4.0 (Serviço Nacional de Aprendizagem Industrial), sobre a Indústria 4.0, para avaliar o nível de maturidade do centro de distribuição de medicamentos da empresa.

Para tanto, este artigo apresenta em sua estrutura, esse tópico de introdução que contextualiza o estudo; seguindo com o referencial teórico que aborda os principais conceitos que fundamentam o estudo; a metodologia; os resultados e discussão; as considerações finais; e por fim, as referências que foram as fontes do estudo.

\section{REFERENCIAL TEÓRICO}




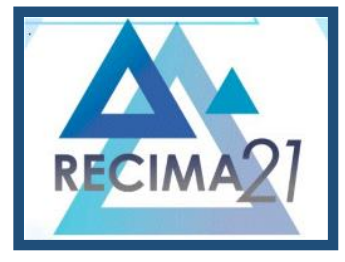

\section{RECIMA21 - REVISTA CIENTÍFICA MULTIDISCIPLINAR}

MODELO DE AVALIAC̃̃O DE MATURIDADE DA INDÚSTRIA 4.0 - ESTUDO DE CASO EM UM CENTRO DE DISTRIBUIÇÃO DE MEDICAMENTOS NA BAIXADA FLUMINENSE/RJ Jorge Luiz Machado, Mariana Gonçalves de Carvalho Wolff, Ariele Silva Moreira Rodrigues, Denise Carvalho Takenaka, Marcos Azevedo Benac

\subsection{Histórico sobre as quatro Revoluções Industriais}

A palavra "revolução" designa mudanças abruptas e radicais (COSTA, 2019). Segundo o dicionário Aulete digital, "revolução" significa: ato de realizar ou sofrer grandes mudanças ou alteração.

As inovações tecnológicas inseridas no processo produtivo, tais como máquina a vapor, tear mecânico e uso de produtos químicos, são fatores que desencadearam a primeira revolução industrial, entre o final do século XVIII e início do século XIX (JUNIOR, 2018).

Segundo Alizon et al. (2009, apud MOREIRA, 2017, p. 18), a segunda revolução industrial, devido a disponibilidade da energia elétrica, deu-se através da substituição do vapor por motores elétricos. Segundo Jensen (1993), "esse período é marcado pela inovação no transporte, na comunicação e na disponibilidade da energia elétrica dentro da fábrica" (apud MOREIRA, 2018, p. 24). Diante disso, o uso da linha de montagem da indústria automobilística, como a Ford Motor Company, foi a que mais se destacou.

De acordo com Coelho (2016), a terceira revolução Industrial iniciou-se no período compreendido de 1950 a 1970, a chamada revolução digital, nas décadas de 1950 a 1970, com o aumento e propagação do uso dos semicondutores, dos computadores, automação e robotização em linhas de produção, com informação armazenada e processada de forma digital, as comunicações, os telefones móveis e a internet (COELHO, 2016). Para Prado (2010, apud Júnior, 2018, p.24): "toma lugar a introdução da eletrônica e tecnologia da informação no processo de produção".

Chegamos à quarta revolução industrial, em curso, onde as empresas precisam transformar toda a sua cadeia de valor por meio da digitalização e soluções inteligentes. Segundo Hajrizi (2016), "os sistemas industriais precisam adotar sistemas complexos que permitam a integração por intermédio da digitalização, uso de estrutura flexível e estratégias utilizando métodos de Inteligência Artificial". A figura 1 ilustra e resume os estágios das quatros revoluções industriais.

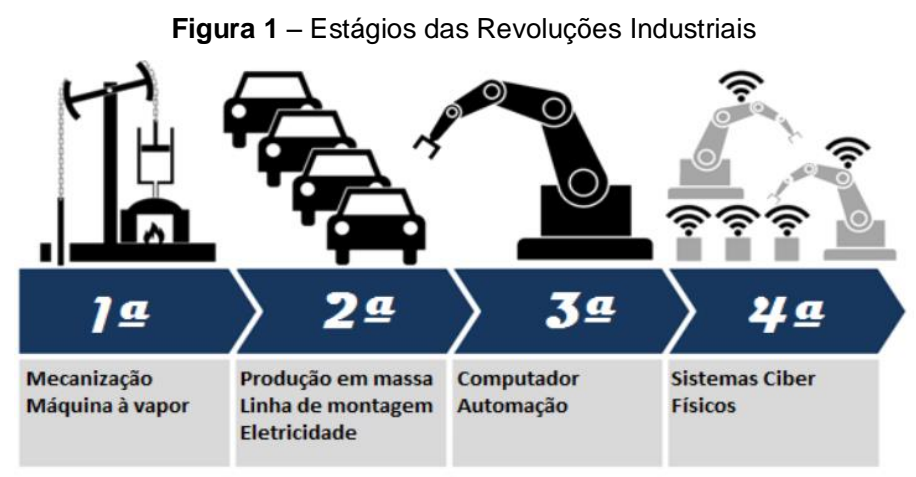

Fonte: Costa (2019). 


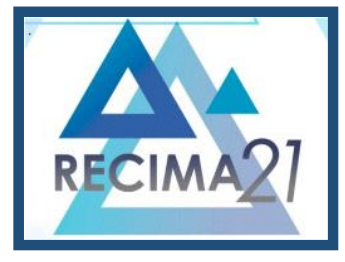

\title{
RECIMA21 - REVISTA CIENTÍFICA MULTIDISCIPLINAR
}

MODELO DE AVALIAÇ̃̃O DE MATURIDADE DA INDÚSTRIA 4.0 - ESTUDO DE CASO EM UM CENTRO DE DISTRIBUIÇÃO DE MEDICAMENTOS NA BAIXADA FLUMINENSE/RJ Jorge Luiz Machado, Mariana Gonçalves de Carvalho Wolff, Ariele Silva Moreira Rodrigues, Denise Carvalho Takenaka, Marcos Azevedo Benac

\subsubsection{Definição de Indústria 4.0}

Para Drath e Horch (2014), conforme citado por Júnior (2018, p.26), utilizado pela primeira vez, na cidade de Hannover, na Alemanha, o termo Indústria 4.0, ganhou sua primeira conceituação, era o vaticínio que a Quarta Revolução Industrial estava em curso, com o apoio do governo federal alemão, e como lema: "Estratégia de alta tecnologia 2020 para a Alemanha".

O grupo de trabalho "Industrie 4.0", formado por Kagermann, Wahlster e Helbig, publicou em 2013, as primeiras recomendações para a implementação e sua visão da indústria 4.0, diz o documento:

\begin{abstract}
"No futuro, as empresas estabelecerão redes globais que incorporarão suas maquinas, sistemas de armazenamento e instalações de produção na forma de Sistemas Ciber-Físicos (Cyber-Physical System - CPS). No ambiente de fabricação, esses sistemas compreendem maquinas inteligentes sistemas de armazenamento e instalações de produção capazes de trocar informações de forma autônoma, acionando ações e controlando-se umas às outras independentemente. Isso facilita melhorias fundamentais nos processos industriais envolvidos na fabricação, engenharia, uso de material e cadeia de suprimentos e gerenciamento do ciclo de vida. As fabricas inteligentes que já estão começando a aparecer, empregam uma abordagem completamente nova para a produção. Os produtos inteligentes são exclusivamente identificáveis, podem estar localizados em todos os momentos e conhecer seu próprio histórico, status atual e rotas alternativas para alcançar seu estado de destino. Os sistemas de manufatura incorporados são conectados verticalmente com processos de negócios dentro de fabricas e empresas e conectados horizontalmente a redes de valor dispersas que podem ser gerenciadas em tempo real - desde o momento em que um pedido e colocado até a logística de saída" (KAGERMANN; WAHLSTER; HELBIG, 2013, p.05 apud JÚNIOR, 2018, p. 26).
\end{abstract}

Para Coelho (2016), o termo "Indústria 4.0": "[...] descreve uma visão do que será uma fábrica no futuro. [...] as fábricas serão muito mais inteligentes, flexíveis, dinâmicas e ágeis. [...] que faz produtos inteligentes, em equipamentos inteligentes, em cadeias de abastecimento inteligentes".

Segundo Hofmann (2017, apud Ribeiro, 2018, p.19): "coloca que o conceito é construído na ideia de um sistema de produção descentralizado, no qual, pessoas, máquinas e recursos interagem naturalmente, tal como uma rede social".

Para Wang et al. (2017), conforme citado por Santana et al. (2019) define: "o termo Indústria 4.0 é um conceito que abrange a cadeia de valor de uma organização, permeando tecnologias, sistemas e processos que permitirão atender a customização em massa por intermédio da flexibilidade em seus projetos, sem sofrer impactos estruturais".

A Indústria 4.0 é descrita como a produção orientada por sistemas ciber-físicos que integram recursos de produção, sistemas de armazenamento, logística, além de necessidades sociais, para estabelecer cadeias globais de criação de valor (STOCK; SELIGER, 2016; S. WANG et al., 2016 apud SANTOS, 2018, p. 10).

Kusiak, (2017, apud SANTOS, 2018, p.11) define, assim, a indústria 4.0: 


\title{
RECIMA21 - REVISTA CIENTÍFICA MULTIDISCIPLINAR
}

\author{
MODELO DE AVALIACÃO DE MATURIDADE DA INDÚSTRIA 4.0 - ESTUDO DE CASO \\ EM UM CENTRO DE DISTRIBUIÇÃO DE MEDICAMENTOS NA BAIXADA FLUMINENSE/RJ \\ Jorge Luiz Machado, Mariana Gonçalves de Carvalho Wolff, Ariele Silva Moreira Rodrigues, \\ Denise Carvalho Takenaka, Marcos Azevedo Benac
}

A manufatura inteligente integra os ativos da manufatura com sensores, sistemas de computação, tecnologias de comunicação, modelagem de dados, controle, simulação e sistemas preditivos. Ela utiliza os conceitos de sistemas ciber-físicos, a internet das coisas, computação em nuvem, computação orientada a serviços, inteligência artificial, e ciência de dados. Uma vez implementados, esses conceitos e tecnologias de transição farão da manufatura a marca da nova revolução industrial. $\mathrm{O}$ autor define seis pilares para a consolidação da manufatura inteligente: tecnologias e processos de manufatura, materiais, dados, engenharia preditiva, sustentabilidade, e compartilhamento de recursos e redes de comunicação (KUSIAK, 2017, apud SANTOS, 2018, p.11).

Segundo Morais, Mouro e Denani (2018), citado por Santos (2018, p.29): "A Indústria 4.0 baseia-se em máquinas, produtos e processos interligados e interdependentes, que coletam e analisam dados, e tomam decisões de acordo com as situações existentes na fábrica [...] permite ganhos em produtividade, qualidade e rentabilidade [...]".

Para estar inserida em um conceito de Indústria 4.0, de acordo com Santos (2018) são necessárias algumas características tecnológicas, como:

- Digitalização: disponibiliza a base para a aquisição de dados em tempo real e de forma remota. O desenvolvimento de produtos e serviços, a fabricação, e a distribuição aos clientes, bem como a digitalização de equipamentos e de produtos são a base para a comunicação, operação e controle remoto dos principais processos de negócio.

- Conectividade: todo o processo de comunicação entre os colaboradores (funcionários) deve ser feito através em redes sem fio e a troca de informações com os clientes via internet. Esta tríade tecnologia - homem-máquina, cumprirá um papel fundamental para a conexão de pessoas, máquinas, dispositivos móveis, sensores, produtos.

- Interoperabilidade: aborda a capacidade de sistemas de informação atuarem de forma integradas (interoperarem), trocam informações e as usa para realizar ações específicas. Lembre-se que os sistemas não são homogêneos, eles realizam funções diferentes, porém, a troca de dados deve ocorrer de forma íntegra e segura. Este sistema pode estar integrado forma interna e externa, ou seja, a empresa pode trocar os dados e as informações em toda a cadeia de valor.

- Adaptabilidade: está relacionada a questões sazonais, ou seja, o sistema precisa ter a capacidade alterar seu estado, se autoadaptar, em resposta a eventos de mudanças de conjunturas. Segundo Santos (2018): "é uma das principais características de sistemas que trabalharão com grandes volumes de dados (Big Data) em tempo real, e estará presente em sistemas descentralizados e inteligentes".

- Escalabilidade: em situações de aumento de volume de produção, a empresa deve ter a capacidade de manter-se em funcionamento e dando as respostas esperadas, ou seja, é a flexibilidade do sistema em atender variações de variedade e volume de demanda.

- Eficiência: com o aumento da comunicação entres os colaboradores e os sistemas, através da introdução de tecnologias inteligentes, entende-se que a cadeia produtiva tende de operar 


\section{RECIMA21 - REVISTA CIENTÍFICA MULTIDISCIPLINAR}

MODELO DE AVALIAC̄̃̃ DE MATURIDADE DA INDÚSTRIA 4.0 - ESTUDO DE CASO EM UM CENTRO DE DISTRIBUIÇÃO DE MEDICAMENTOS NA BAIXADA FLUMINENSE/RJ Jorge Luiz Machado, Mariana Gonçalves de Carvalho Wolff, Ariele Silva Moreira Rodrigues, Denise Carvalho Takenaka, Marcos Azevedo Benac

com pouco ou nenhum desperdício ou ociosidade de recursos, ou seja, tornar os sistemas mais eficientes e responsivos.

- Capacidade ou manutenção preditiva: é baseado em informações como dados histórico, algoritmo de compreensão de padrões (aprendizado das máquinas - M2M), dados em tempo real de antever seu estado, comportamento, ou funcionalidade, para um determinado horizonte de tempo futuro, qualitativamente ou quantitativamente.

- Reconfigurabilidade: em caso de falhas o sistema deve ser altamente reconfigurável e autoconfigurável, assim como seus componentes, em toda cadeia produtiva. Para Santos (2018): "esta é uma característica relacionada no estado da arte da Indústria 4.0 e possui constitui-se numa ampla oportunidade de pesquisa e desenvolvimento de soluções industriais".

\subsection{Os pilares que fundamentam as tecnologias habilitadoras}

Neste tópico vamos destacar a importância das tecnologias habilitadoras, termo utilizado por Venturelli (2017) e adotado por este autor que servem de pilares da Indústria 4.0.

A indústria 4.0 baseia-se em pilares como: Internet das Coisas (IoT), cloud computing, Inteligência Artificial (I.A) das máquinas (M2M), impressão 3D, Data mining (Mineração de dados), big data, cyber-physical systems (CPS), RFID, blockchain, realidade aumentada, realidade virtual, impressão 3D, Internet das industrias (IIoT), AGV e ciber segurança, serão conceituadas e a sua existência ou não na empresa serão analisadas. A Figura 2 identifica os pilares para a formação da indústria 4.0.

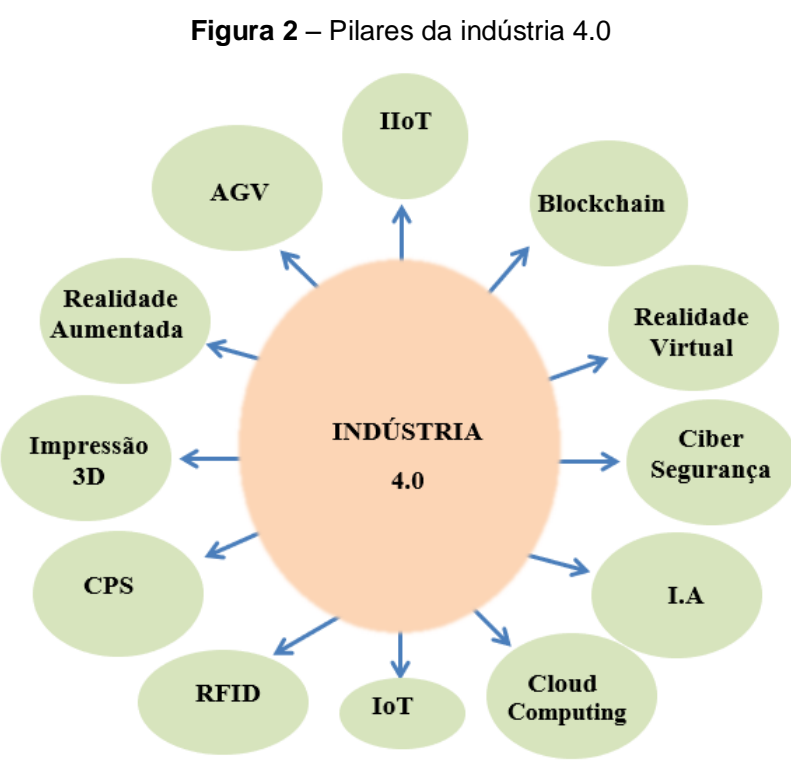

Fonte: Adaptado pelo autor, Hermann et al. (2016) e Morais, Moura e Denani (2018). 


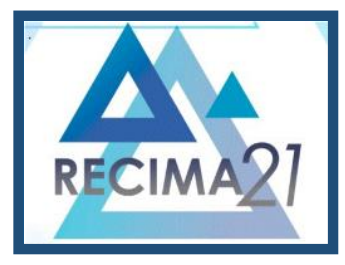

\title{
RECIMA21 - REVISTA CIENTÍFICA MULTIDISCIPLINAR
}

\author{
MODELO DE AVALIAÇÃO DE MATURIDADE DA INDÚSTRIA 4.0 - ESTUDO DE CASO \\ EM UM CENTRO DE DISTRIBUIÇÃO DE MEDICAMENTOS NA BAIXADA FLUMINENSE/RJ \\ Jorge Luiz Machado, Mariana Gonçalves de Carvalho Wolff, Ariele Silva Moreira Rodrigues, \\ Denise Carvalho Takenaka, Marcos Azevedo Benac
}

Venturelli (2019) divide a transformação digital de uma Indústria 4.0 em três estágios: o primeiro, são os pré-requisitos que compreendem a automação, otimização e convergência; o segundo, engloba a digitalização básica como Internet das Coisas (IoT), cloud computing, cibersegurança e big data, por último as tecnologias habilitadoras, propriamente dita, como: Inteligência Artificial (I.A) das máquinas (M2M), impressão 3D, Data mining, cyber-physical systems (CPS), $R F I D$, blockchain, realidade aumentada, realidade virtual, robôs, Internet das industrias (IloT) e AGV.

\subsubsection{Internet das coisas (IOT)}

Segundo Venturelli (2019) é um conceito de interconectar via rede (internet), equipamentos e dispositivos, com o objetivo de coletar dados e informações para análise e tomada de decisões, de forma remota. Através de um sistema eletrônico conectado no equipamento, coleta e envia os dados para um repositório, normalmente na nuvem (cloud), utilizando a rede mundial de computadores. $\mathrm{Na}$ indústria essa tecnologia permite tomada de decisões baseado em coleta de dados remotamente, com diversos usuários interligados. Como exemplo, podemos citar um equipamento enviando dados para análise de manutenção de seu fabricante, monitorando em tempo real, sem a necessidade da intervenção do cliente.

\subsubsection{Ciber-segurança}

Fator primordial para a segurança da indústria multiconectada. A ciber-segurança é técnica de proteger sistemas, dados e informações da empresa contra os ataques de hackers. Segundo Morais, Moura e Denani (2018): "com o aumento da conectividade e uso de protocolos de comunicação padrão envolvidos na Indústria 4.0, a necessidade de proteger os sistemas críticos e linhas de produção industrial de ameaças cibernéticas aumentarão dramaticamente".

Tem por finalidade o controle de permissões, autenticações e validações de ações de leitura, processamento e escrita, através software de segurança, firewall e servidores da empresa em salas cofres. Além de procedimentos de segurança, equipamentos analisam comportamento de tráfego e controlam autorizações na rede de comunicação. Em uma indústria, sistemas de ciber-segurança permitem interconectar cadeia de valor com segurança para os usuários e colaboradores. A análise de dados e usuários de um controle operacional de uma refinaria, conectada ao sistema logístico externo, sendo monitorada, é um exemplo de ciber-segurança.

\subsubsection{Cloud Compunting}

Segundo Venturelli (2019) é um conceito de interconectar via rede (internet), equipamentos e dispositivos, com o objetivo de coletar dados e informações para análise e tomada de decisões, de forma remota, ou seja, processando e armazenando dados em computadores virtuais e servidores, utilizando como meio a internet. Essa tecnologia serve para o uso de computadores, infraestrutura e 


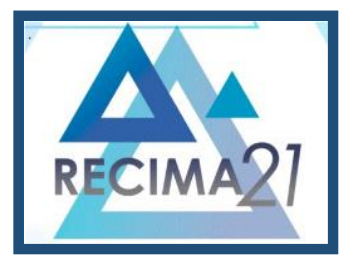

\section{RECIMA21 - REVISTA CIENTÍFICA MULTIDISCIPLINAR}

MODELO DE AVALIACÃO DE MATURIDADE DA INDÚSTRIA 4.0 - ESTUDO DE CASO EM UM CENTRO DE DISTRIBUIÇÃO DE MEDICAMENTOS NA BAIXADA FLUMINENSE/RJ Jorge Luiz Machado, Mariana Gonçalves de Carvalho Wolff, Ariele Silva Moreira Rodrigues, Denise Carvalho Takenaka, Marcos Azevedo Benac

software como serviço. De acordo com Morais, Moura e Denani (2018), "mas com a Indústria 4.0 um maior número de tarefas relacionadas a produção requer um maior intercâmbio de dados entre os locais e empresas".

Seu funcionamento são plataformas especializadas que permitem criar ambientes de processamento, como por exemplo, o software Azure Microsoft, conexão em lot, análise de dados Data Science, tudo virtualmente. Através de um sistema eletrônico conectado no equipamento, coleta e envia os dados para um repositório, normalmente na nuvem (cloud), utilizando a rede mundial de computadores. $\mathrm{Na}$ indústria essa tecnologia permite tomada de decisões baseado em coleta de dados remotamente, com diversos usuários interligados. Como exemplo, podemos citar um equipamento enviando dados para análise de manutenção de seu fabricante, monitorando em tempo real, sem a necessidade da intervenção do cliente.

\subsubsection{Big Data}

De acordo com AKERKAR (2014), citado por Nascimento et al. (2017), Big Data refere-se a conjuntos de dados, cujo tamanho está além das capacidades da tecnologia de banco de dados atual. É um campo emergente onde a tecnologia inovadora oferece alternativas para resolver os problemas inerentes que aparecem quando se trabalha.

Big data é uma ferramenta de processamento de banco de dados diversos, estruturados ou não, para análise, permitindo abstração. Tem por finalidade unir diversos bancos de dados, dentro de uma cadeia de valor de negócios, analisando em tempo real o comportamento. Esses diversos bancos de dados espalhados, do cliente, planta produtiva, logística e consumo, funcionam gerando dados, estruturados ou não e são analisados, principalmente, para tomada de decisões mais assertiva para os gestores da empresa e, permitindo, ainda, automação de processos (aprendizado de máquina - M2M) por identificação de comportamento. Como exemplo, na tomada de decisões de um supervisor de logística, qual seria o melhor produto a entrar em uma linha de produção nas próximas $48 \mathrm{~h}$ em função de demanda e alteração de rota logística em função de mudança de clima, de forma automática.

\subsubsection{Internet industrial das coisas (IloT)}

Para Venturelli (2019), a internet industrial das coisas é um conceito de conectar via Cloud Computing, um conjunto de dados estruturados dentro da cadeia de valor da organização. Sua utilização é a partir de diversas estruturas espalhadas e todas conectadas na cadeia de valor da indústria, como por exemplo, o setor de logística, independentemente da localização, vendo o processo produtivo e interferindo no mesmo instante, permitindo, assim, a diminuição dos Led Times e tomada de decisão do supervisor de logística em tempo real. Um exemplo prático, é um cliente de 


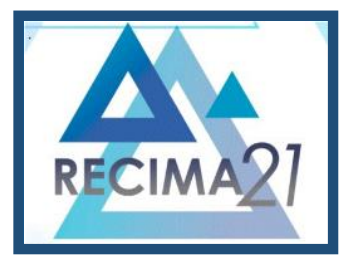

\section{RECIMA21 - REVISTA CIENTÍFICA MULTIDISCIPLINAR}

MODELO DE AVALIAÇ̃̃O DE MATURIDADE DA INDÚSTRIA 4.0 - ESTUDO DE CASO EM UM CENTRO DE DISTRIBUIÇÃO DE MEDICAMENTOS NA BAIXADA FLUMINENSE/RJ Jorge Luiz Machado, Mariana Gonçalves de Carvalho Wolff, Ariele Silva Moreira Rodrigues, Denise Carvalho Takenaka, Marcos Azevedo Benac

um CD de medicamentos que se conecta ao planejamento virtualizado e produtivo da fábrica se adaptando mutualmente.

\subsubsection{Inteligência Artificial (I.A)}

Segundo Mendonça, Andrade e Neto (2018), o reconhecimento de voz, a Cortana e Alexia são exemplos do dia a dia onde a I.A está presente, na vida das pessoas e empresas. Com essa popularização é possível afirmar que a I.A se encontra em novo estágio evolutivo, e que alguns denominam de I.A 2.0.

De acordo com Pan (2016) citado por Mendonça et al. (2018) a integração da I.A com demandas industriais forçou mudanças significativas como os serviços são prestados. Pan (2016) cita alguns exemplos: O robô de bate-papo Xiaobing, desenvolvido pela Microsoft, orienta a transformação de uma interface gráfica tradicional para uma interface interativa com entendimento natural e emocional. A I.A e a robótica, gerarão uma reviravolta nas organizações com relação as funções administrativas nas quais ela passará a ocupar, isso acontecerá devido a I.A ter facilidade de fazer correspondências de padrões e automatizar processos, o que faz a adoção da tecnologia ser recomendável. Essa introdução da I.A cada vez mais ao mercado e nas organizações, tem como aspectos positivos a redução de custos, ganhos de eficiência e a facilidade de pequenas empresas que exploram fortemente o aspecto da inovação, mas pontos negativos também são observados, tais como: perda de postos de trabalho, prestação de contas e responsabilidade, mudanças legais, de relatos financeiros e riscos (SCHWAB, 2016 apud MENDONÇA; ANDRADE; NETO, 2018)

\subsection{Adaptação de empresa à avaliação de maturidade da Indústria 4.0 - ACATECH.}

Existem diversas problemáticas em captar holisticamente os conceitos e ideias da Indústria 4.0, além das aplicações derivadas dela. As empresas não são capazes de relacionar, de forma estratégica, aos benefícios da Indústria 4.0 para o seu negócio, e também, esbarram com problemas em determinar o seu estado atual de desenvolvimento em relação a visão da Indústria 4.0 (SCHUMACHER; EROL; SIHN, 2016; SANTOS, 2018).

Lichtblau et al. (2015 apud, Santos, 2018, p.50) é outro autor que observou em um relatório sobre a pesquisa de maturidade, que algumas empresas apresentam alguns obstáculos com relação a Indústria 4.0. Lichtblau et al. (2015), enumera a falta de clareza sobre os benefícios econômicos, falta de conhecimento ou mão de obra qualificada, falta de normatização e padrões, falta de confiança na segurança dos dados, questões legais não resolvidas, falta de cultura corporativa para os conceitos da Indústria 4.0, falta de informação sobre a necessidade do mercado, infraestrutura de rede de internet inadequada, falta de recursos financeiros para realizar os investimentos, burocracias internas e questões regulatórias e falta de abertura da força de trabalho para a digitalização. 


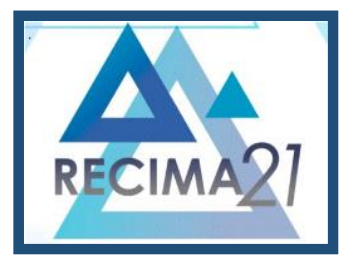

\section{RECIMA21 - REVISTA CIENTÍFICA MULTIDISCIPLINAR}

MODELO DE AVALIAÇ̃̃O DE MATURIDADE DA INDÚSTRIA 4.0 - ESTUDO DE CASO EM UM CENTRO DE DISTRIBUIÇÃO DE MEDICAMENTOS NA BAIXADA FLUMINENSE/RJ Jorge Luiz Machado, Mariana Gonçalves de Carvalho Wolff, Ariele Silva Moreira Rodrigues, Denise Carvalho Takenaka, Marcos Azevedo Benac

Já a afirmação de Schumacher, Erol e Sinn (2016) se dá por meio da experiências de workshop de orientação estratégica com várias empresas e preocupado com essa falta de visão sobre o tema caracterizado pelas incertezas e as necessidades das empresas de manufatura, com relação às transformações da Indústria 4.0, novos métodos e ferramentas são necessários para prover um guia e o suporte para o alinhamento das estratégias de negócios e operações com as novas tecnologias emergentes, o que o levou a desenvolver um modelo de avaliação de maturidade, baseado nas recomendações do relatório final da Plattform Indusrie 4.0, conhecido como ACATECH. Segundo Santos (2018) as empresas, no momento de identificar o caminho correto e as áreas concretas para o desenvolvimento de ações, programas e projetos, falham.

Baseado nas afirmações dos autores supracitados, esta pesquisa fundamenta-se no modelo proposto por Schumacher, Erol e Sihn (2016) com a finalidade de analisar estas afirmações e localizar em que nível de maturidade a empresa, está inserida, de acordo o modelo de maturidade de ACATECH. Segundo Ribeiro (2018): "O modelo proposto avalia cinco dimensões da empresa como as pessoas, os processos de manufatura, os produtos, as tecnologias avançadas e seu modelo de negócio".

\subsection{Guia de avaliação de maturidade da ACATECH}

$\mathrm{Na}$ Alemanha, a National Academy of Science and Engineering (ACATECH) elabora O Guia de maturidade da Indústria 4.0 (Schuh et al., 2017). Considerado um modelo de avaliação de maturidade em si, e um guia para que as empresas entendam o caminho que devam trilhar para o desenvolvimento da Indústria 4.0, e porque não, construam seus modelos próprios, tornando às empresas de manufatura abertas as novas tecnologias, levando-as ao aprendizado, e ágeis nas respostas aos mercados do futuro e na flexibilidade da cadeia de valor. O guia determina em qual estágio as empresas encontram-se atualmente no processo de transformação digital, a partir de perspectivas, organizacionais, culturais e tecnológicas, conforme a Figura 3, que ilustra os níveis de maturidade detalhado abaixo, se a empresa está no caminho de transformação digital rumo a Indústria 4.0.

Figura 3 - Níveis de maturidade para a Indústria 4.0 


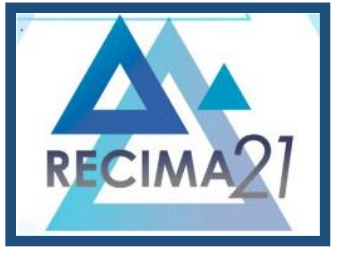

\section{RECIMA21 - REVISTA CIENTÍFICA MULTIDISCIPLINAR}

MODELO DE AVALIAC̄̃̃ DE MATURIDADE DA INDÚSTRIA 4.0 - ESTUDO DE CASO EM UM CENTRO DE DISTRIBUIČ̃̃O DE MEDICAMENTOS NA BAIXADA FLUMINENSE/RJ Jorge Luiz Machado, Mariana Gonçalves de Carvalho Wolff, Ariele Silva Moreira Rodrigues, Denise Carvalho Takenaka, Marcos Azevedo Benac

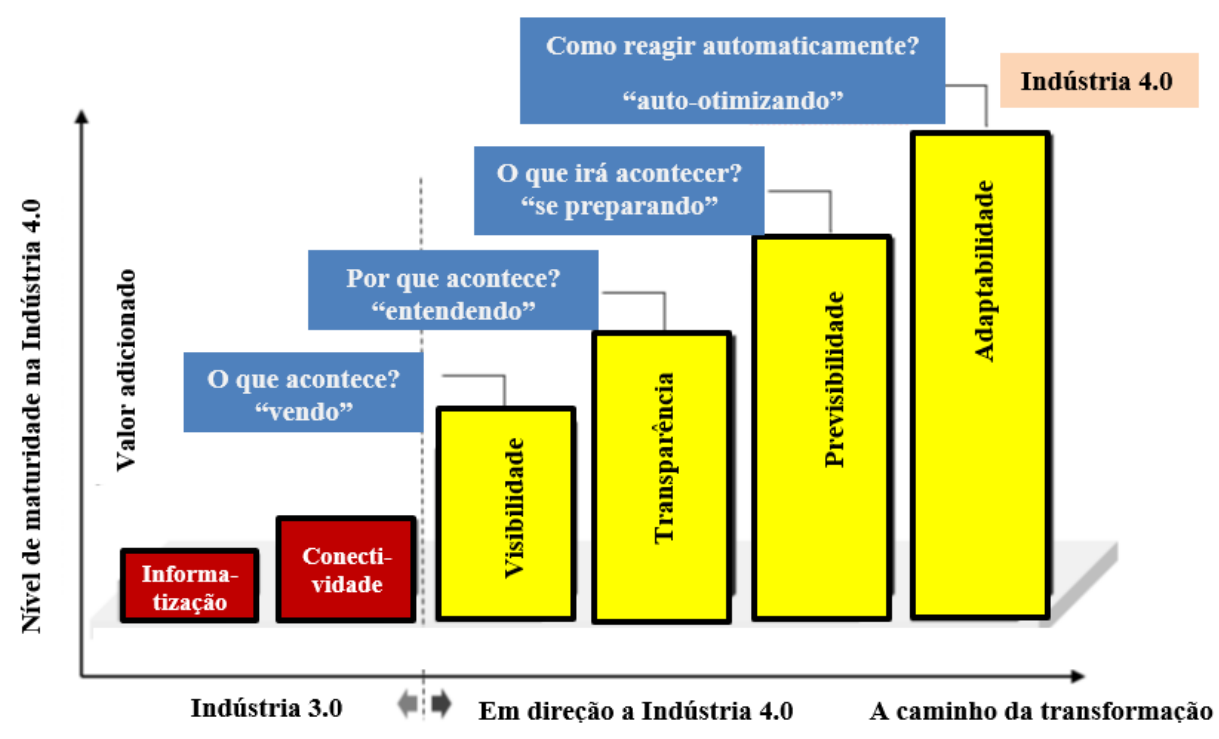

Fonte: Adaptado pelo autor, do modelo ACATECH de Schuh et al. (2017).

Segundo Santos (2018), o guia sugere seis estágios para o desenvolvimento do processo de transformação:

1) Informatização: provê a base para digitalização. Ainda que com sistemas operando de forma isolada, a informatização se encontra bem avançada em muitas empresas, e é usada para execução de tarefas repetitivas de maneira mais eficiente. A informatização entrega benefícios, possibilitando uma produção mais barata, e um grau de precisão, sem o qual não seria possível a produção de muitos dos produtos modernos atuais. Importantes exemplos desse estágio são as máquinas CNC não integradas a sistemas CAD, ou mesmo sistemas de execução de manufatura (MES), e outros sistemas de aplicação não integrados ao ERP.

2) Conectividade: no estágio de conectividade, os sistemas de negócios informatizados são atualizados ou substituídos por sistemas conectados. Neste estágio indica que parte dos sistemas operacionais permitem a conectividade e interoperabilidade, entretanto a integração completa dos sistemas de informação e sistemas de operação ainda não está implantada.

3) Visibilidade: é dedicado a prover visibilidade de informações, coletadas através do sensoriamento e aquisição de dados, não se restringindo somente aos dados da produção, mas de toda a organização, e disponibilizados para os envolvidos ao longo da cadeia de valor, em uma grande coleção de dados (Big Data), através da integração dos sistemas de planejamento de recursos (ERP), sistemas de gestão do ciclo de vida do produto (PLM), e sistemas de execução de manufatura (MES). Neste estágio, os gerentes tomam decisões baseadas em dados e não em experiências.

4) Transparência: com a estrutura digital pronta, este estágio compreende o entendimento dos dados, e consequentemente dos problemas, passando a entender porque eventos passados e presentes ocorreram ou estão ocorrendo, em meio aos complexos sistemas que foram implementados, ou seja, através da sistematização da análise das informações, a identificação da 


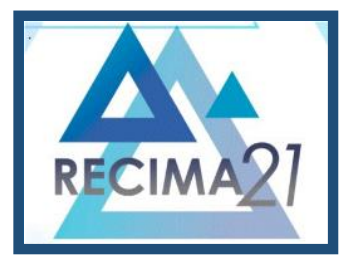

\section{RECIMA21 - REVISTA CIENTÍFICA MULTIDISCIPLINAR}

MODELO DE AVALIAÇÃO DE MATURIDADE DA INDÚSTRIA 4.0 - ESTUDO DE CASO EM UM CENTRO DE DISTRIBUIÇÃO DE MEDICAMENTOS NA BAIXADA FLUMINENSE/RJ Jorge Luiz Machado, Mariana Gonçalves de Carvalho Wolff, Ariele Silva Moreira Rodrigues, Denise Carvalho Takenaka, Marcos Azevedo Benac

causa raiz dos problemas, e cria padrões de ação para a rápida resolução dos mesmos, em síntese, busca a geração de conhecimento. As características das tecnologias habilitadoras, neste estágio, são: os sistemas de mineração de dados (Data Mining) e softwares aplicados de simulação e análise probabilística. A transparência pode ser usada para: o monitoramento de máquinas e equipamentos, da linha de produção, sistemas logísticos, monitoramento de inventários, além de informações de vendas, pedidos, e outras informações relevantes ao negócio.

5) Capacidade preditiva: a empresa estará apta a simular diferentes cenários futuros e identificar com mais clareza e precisão os mais prováveis, baseados em algoritmos probabilísticos inteligentes de raciocínio baseado em casos (CBR - case-based reasoning). Neste nível, a empresa pode dar respostas automatizadas como antecipação a paradas de produção, ruptura de estoque, atrasos nas entregas de pedidos, variações de demanda, entre outras que podem afetar eficiência e a lucratividade. Neste estágio as decisões são tomadas por humanos.

6) Adaptabilidade: ocorre quando a empresa é capaz de usar dados do modelo digital para tomar decisões que possibilitem os melhores resultados em menores espaços de tempo possíveis, e implementar as ações de resposta de forma automática, com pouca ou nenhuma intervenção humana.

\section{METODOLOGIA DA PESQUISA}

\subsection{Tipos de pesquisas}

Gil (2007, p. 17), define a importância da pesquisa, como: “(...) procedimento racional e sistemático que tem como objetivo proporcionar respostas aos problemas que são propostos". Portanto, a pesquisa desenvolve-se por várias fases; isto é, desde a formulação do problema até a apresentação e discussão dos resultados.

Neste estudo, no que se refere aos objetivos, a pesquisa possui características exploratórias. De acordo com Selltiz et al. (1967), este tipo de pesquisa tem por objetivo proporcionar maior vínculo com o problema, visando torná-lo mais cristalino ou a constituir teses. Para Gil (1991, p.41), na maioria dos estudos acadêmicos, as pesquisas exploratórias, demandam: (1) levantamento bibliográfico; (2) entrevistas com pessoas que tiveram experiências práticas com o problema pesquisado; e (3) análise de exemplos que "estimulem a compreensão".

Pesquisas exploratórias têm como objetivo principal o aprimoramento de convicções ou a descoberta de suspeições. Sua elaboração requer bastante flexibilidade, de tal forma que, viabilize a consideração dos mais múltiplos aspectos relativos ao caso a ser estudado. Para Gil (1991, p. 41): "embora o planejamento da pesquisa exploratória seja bastante flexível, na maioria dos casos assume a forma de pesquisa bibliográfica ou de estudo de caso". De acordo com Migueles (2004) apud Schutz et al. (2018): "o objetivo da pesquisa exploratória é situar-se em um problema sobre o 


\section{RECIMA21 - REVISTA CIENTÍFICA MULTIDISCIPLINAR}

MODELO DE AVALIAC̄̃̃ DE MATURIDADE DA INDÚSTRIA 4.0 - ESTUDO DE CASO

EM UM CENTRO DE DISTRIBUIÇÃO DE MEDICAMENTOS NA BAIXADA FLUMINENSE/RJ

Jorge Luiz Machado, Mariana Gonçalves de Carvalho Wolff, Ariele Silva Moreira Rodrigues, Denise Carvalho Takenaka, Marcos Azevedo Benac

qual o pesquisador não tem informações ou conhecimentos suficientes para traçar estratégias que possibilitem atingir seus objetivos".

Além disso, quanto à natureza, o presente estudo é uma investigação básica, cuja finalidade é gerar novos conhecimentos para avançar o tema "Indústria 4.0" sem aplicação prática prevista, para um problema específico.

Quanto ao procedimento é um estudo de caso, que requer uma abordagem do problema através de uma pesquisa qualitativa. Segundo Marconi e Lakatos (2009), essa abordagem tem como preceito investigar e desvendar aspectos mais intrínsecos: "permitindo descrever detalhadamente investigações, atitudes e tendências de comportamento, buscando interpretar e compreender as relações acerca da complexidade do problema sem o uso de recursos estatísticos". Para Oliveira (2007, p. 37 apud Schutz et al., 2018): "A pesquisa qualitativa tem um processo de reflexão e análise da realidade através da utilização de métodos e técnicas para compreensão detalhada do objeto de estudo em seu contexto histórico [...]".

O foco do estudo é analisar o nível de maturidade para o desenvolvimento da indústria 4.0, através dos pilares que a fundamentam (tecnologias habilitadoras). A elaboração do estudo contou com a utilização de ferramentas em técnicas de pesquisa, através de visitas a empresa e um questionário, baseado no método Delphi adaptado, para a coleta de dados, ideal para o estudo de caso em questão.

\subsection{Seleção dos artigos}

Foi realizada uma pesquisa para a construção de uma base de dados (artigos, teses, TCCs e dissertações) na realização deste estudo, de acordo com a Figura 3. Os portais buscados foram: Scielo, Scopus, Google Acadêmico (Scholar), Biblioteca BMD da Universidade de Brasília (UNB) e Periódicos da CAPES. Esta busca resultou em 54 artigos, dos quais nove foram escolhidos como documentos base, deste trabalho, conforme referenciado no Quadro 1.

Figura 4 - Fluxograma da metodologia da pesquisa 


\section{RECIMA21 - REVISTA CIENTÍFICA MULTIDISCIPLINAR}

MODELO DE AVALIAC̄̃O DE MATURIDADE DA INDÚSTRIA 4.0 - ESTUDO DE CASO EM UM CENTRO DE DISTRIBUICÃO DE MEDICAMENTOS NA BAIXADA FLUMINENSE/RJ

Jorge Luiz Machado, Mariana Gonçalves de Carvalho Wolff, Ariele Silva Moreira Rodrigues, Denise Carvalho Takenaka, Marcos Azevedo Benac

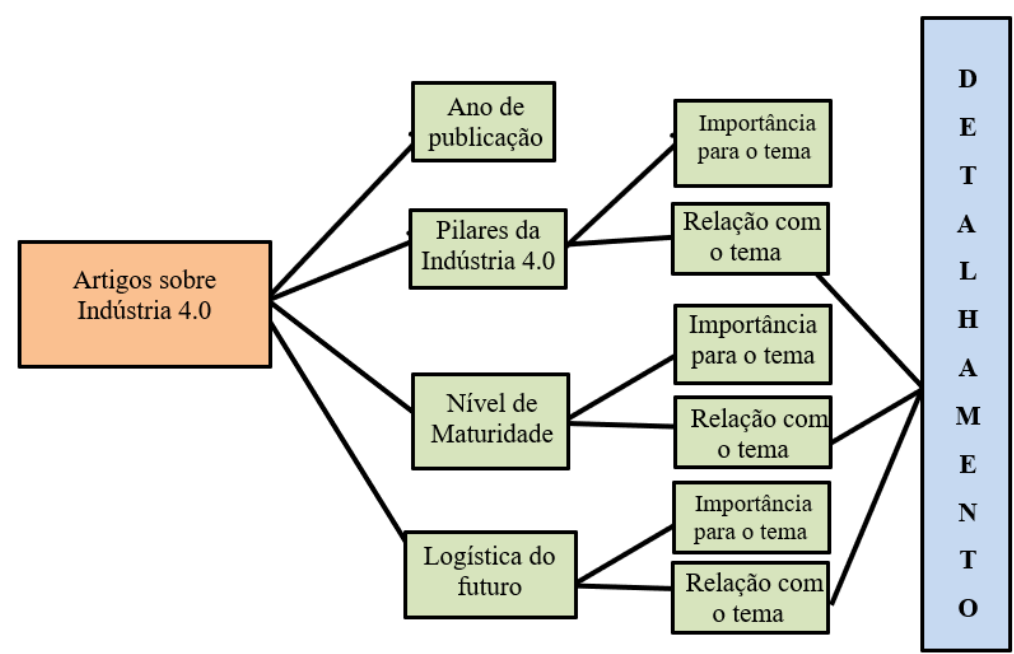

Fonte: Elaborado pelos autores (2020).

As palavras-chaves utilizadas para pesquisas nas bases de dados foram: indústria 4.0, fábricas inteligentes, os pilares da indústria 4.0 e logística 4.0, cuja principal ferramenta utilizada para o levantamento documental e revisão bibliográfica deste estudo foi o site de pesquisa Google.

Quadro 1- Documentos base para a pesquisa

\begin{tabular}{|l|c|c|c|c|}
\hline \multicolumn{1}{|c|}{ TÍTULO } & AUTOR(ES) & ANO & TIPOLOGIA & FONTE \\
\hline Rumo à Indústria 4.0 & Coelho & 2016 & Dissertação & FCTUC \\
\hline $\begin{array}{l}\text { Logística 4.0: conceitos e aplicabilidade: uma } \\
\text { pesquisa-ação em uma empresa de } \\
\text { tecnologia para mercado automobilístico }\end{array}$ & $\begin{array}{c}\text { Freitas, Fraga } \\
\text { e Souza }\end{array}$ & 2016 & Artigo & Caderno PAIC \\
\hline $\begin{array}{l}\text { Logística enxuta e endereçamento: redução } \\
\text { de custos de armazenagem e movimentação }\end{array}$ & $\begin{array}{c}\text { Ziquinato, } \\
\text { Silva e } \\
\text { Delforno }\end{array}$ & 2016 & Monografia & USF \\
\hline $\begin{array}{l}\text { Proposta de adaptação de modelo de } \\
\text { Maturidade para avaliação de indústrias } \\
\text { brasileiras em Indústria 4.0 }\end{array}$ & Ribeiro & 2018 & $\begin{array}{c}\text { Projeto de } \\
\text { graduação }\end{array}$ & UNB \\
\hline $\begin{array}{l}\text { Proposta de modelo de avaliação de } \\
\text { maturidade da Indústria 4.0 }\end{array}$ & Santos & 2018 & Dissertação & ISEC \\
\hline $\begin{array}{l}\text { ldentificação dos impactos da Indústria 4.0 } \\
\text { nas organizações: uma revisão sistemática } \\
\text { de literatura }\end{array}$ & Silva & 2018 & $\begin{array}{c}\text { Trabalho de } \\
\text { Conclusão de } \\
\text { curso }\end{array}$ & UTFPR \\
\hline $\begin{array}{l}\text { A integração entre conhecimento, inovação e } \\
\text { indústria 4.0 nas organizações }\end{array}$ & Morais, Moura \\
e Denani & 2018 & Artigo & $\begin{array}{c}\text { Brazilian } \\
\text { Journal of } \\
\text { Development }\end{array}$ \\
\hline $\begin{array}{l}\text { Princípios e Cenários da Indústria 4.0: Uma } \\
\text { Revisão de Literatura }\end{array}$ & Costa & 2019 & Artigo & $\begin{array}{c}\text { IX } \\
\text { ConBRepro }\end{array}$ \\
\hline $\begin{array}{l}\text { Avaliação do Nível de Maturidade da Indústria } \\
\text { 4.0: O Caso de uma Empresa Estratégica de } \\
\text { Defesa }\end{array}$ & Silva e Rocha & 2019 & Artigo & $\begin{array}{c}\text { Journal } \\
\text { Future }\end{array}$ \\
\hline
\end{tabular}

Fonte: Elaborado pelos autores (2020).

\subsection{Método Delphi Normativo Adaptado}

ISSN: 2675-6218 - RECIMA21 - Ciências Exatas e da Terra, Sociais, da Saúde, Humanas e Engenharia/Tecnologia 


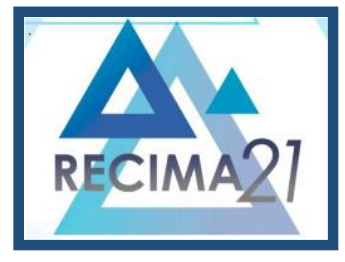

\section{RECIMA21 - REVISTA CIENTÍFICA MULTIDISCIPLINAR}

MODELO DE AVALIAÇ̃̃O DE MATURIDADE DA INDÚSTRIA 4.0 - ESTUDO DE CASO EM UM CENTRO DE DISTRIBUIÇÃO DE MEDICAMENTOS NA BAIXADA FLUMINENSE/RJ Jorge Luiz Machado, Mariana Gonçalves de Carvalho Wolff, Ariele Silva Moreira Rodrigues, Denise Carvalho Takenaka, Marcos Azevedo Benac

Para Facione (1990 apud Marques e Freitas, 2017), dentre as metodologias de pesquisa qualitativas, o método Delphi é uma técnica de investigação que consiste num conjunto de questionários que são respondidos de maneira sequencial, cujo objetivo é encontrar um consenso entre os especialistas no tema onde os resultados são analisados pelos pesquisadores entre cada rodada de questionários de modo a subsidiar tomadas de decisão nas organizações. De acordo com Marques e Freitas (2017) o anonimato é a característica mais importante do método Delphi, assegurando a redução dos efeitos de vieses pessoais.

Marques e Freitas (2017) descrevem os três tipos de estudos Delphi: o convencional, o normativo e o Policy Delphi. O normativo, utilizado neste estudo, segundo Yousuf (2007 apud Marques e Freitas, 2017), procura-se estruturar e projetar um determinado assunto, mas com base no que é desejável e não no que é provável que aconteça. Para Okoli e Pawlowski (2004 apud Santos, 2018), o processo para condução de um estudo Delphi compreende três fases: a primeira, chamada de brainstorming, que engloba os questionários 1 e 2 , a fase seguinte é o estreitamento que trata dos resultados do questionário 3 e, a terceira e última fase, é o ranking, questionário 4, o resultado final.

Devido à pandemia de Covid-19, foi necessária a adaptação do método Delphi, em virtude do distanciamento social, estabelecidos por leis estaduais e municipais, reduzindo as etapas e as rodadas dos questionários. Os questionários elaborados para esse estudo são os estruturados e semiestruturados, sendo por meio de escalas de importância, como, por exemplo, a escala de Likert. Segundo Mirand et al., (2007 apud Marques e Freitas, 2017): "essas escalas são as mais comuns nesses estudos, principalmente as de cinco pontos, mas há quem use escalas com mais pontos ou outras opções de resposta".

\subsection{Coleta de dados}

As atividades previstas abarcavam a identificação das competências específicas e determinam o grau de importância, para a questão da pesquisa proposta, portanto, a utilização do método Delphi foi a mais adequada para a obtenção de informações dos especialistas, neste estudo o supervisor de logística e o gerente de TI. Os dados coletados foram oficializados através do TCLE (Anexo I) aos respondentes dos questionários e anexo estão relacionados nos apêndices "C", "D" e "E".

\section{RESULTADOS E DISCUSSÃO}

\subsection{A organização}

A empresa de distribuição de medicamentos atua no mercado farmacêutico por mais de 30 anos. É uma empresa consolidada no Estado do Rio de Janeiro que possui um grande centro de 


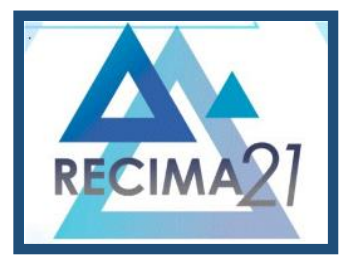

\section{RECIMA21 - REVISTA CIENTÍFICA MULTIDISCIPLINAR}

MODELO DE AVALIAÇÃO DE MATURIDADE DA INDÚSTRIA 4.0 - ESTUDO DE CASO EM UM CENTRO DE DISTRIBUIÇÃO DE MEDICAMENTOS NA BAIXADA FLUMINENSE/RJ Jorge Luiz Machado, Mariana Gonçalves de Carvalho Wolff, Ariele Silva Moreira Rodrigues, Denise Carvalho Takenaka, Marcos Azevedo Benac

distribuição na sua matriz totalizando um espaço de $10.000 \mathrm{~m} 2$. Localizada em um parque industrial na Região Metropolitana do Rio de Janeiro e, recentemente, expandiu-se para o Estado do Espírito Santo, abrindo uma filial naquele Estado, com o objetivo de atender melhor a sua logística, de maneira mais eficiente a toda a sua rede de clientes.

Com 66 fornecedores (laboratórios farmacêuticos) num total de 89 linhas diferentes. As vendas dos produtos de um determinado laboratório são em sua totalidade feitas por operação logística, isto é, nossos vendedores não efetuam vendas dessa linha. O que ocorre é uma terceirização da entrega por parte do Fabricante que diferentemente dos outros em sua maioria, promovem as negociações de vendas a partir do canal "Produtor" direto para o "Varejista" ao invés de seguir a lógica "Produtor-Distribuidor".

A empresa atende a drogarias em todo território do estado do Estado do Rio de Janeiro e o Estado do Espírito Santo e tem como principal produto a linha de Genéricos (60\% do negócio), Similares (22,3\%), Não-Medicamentos (13,3\%) e Referências (4,4\%), (Dados de documentos originais da empresa).

\subsubsection{Relação dos 4V's de Produção}

Ainda que as operações de produção sejam análogas mutuamente na forma de transformar os recursos de input (entrada) em output (saída) de bens e serviço, apresentam distinção em quatro aspectos importantes: volume, variedade, variação e visibilidade.

\subsubsection{Volume}

A empresa de distribuição de medicamentos entrega anualmente aproximadamente 60.000.000 de unidades. $O$ alto volume incide na grande quantidade de funcionários que a empresa deve ter para atender à demanda. Além disso, a automatização do processo faz-se necessária para acelerar a operação como também para evitar erros de contagem.

\subsubsection{Variedade}

A empresa trabalha com uma vasta variedade de medicamentos. Seu portfólio soma um total de 5971 SKU's ativos atualmente, segmentados em mais de 100 classes terapêuticas. A implicação de tamanha variedade, leva a empresa ser mais flexível e atender melhor às necessidades de seus clientes. Cada produto varia muito no que tange seu custo unitário.

\subsubsection{Variação}

Por se tratar de produtos básicos para o consumidor final, não há variações que nos leve a considerar seu negócio como estritamente sazonal. Entretanto, alguns produtos recebem influência 


\section{RECIMA21 - REVISTA CIENTÍFICA MULTIDISCIPLINAR}

MODELO DE AVALIACÃO DE MATURIDADE DA INDÚSTRIA 4.0 - ESTUDO DE CASO EM UM CENTRO DE DISTRIBUIÇÃO DE MEDICAMENTOS NA BAIXADA FLUMINENSE/RJ Jorge Luiz Machado, Mariana Gonçalves de Carvalho Wolff, Ariele Silva Moreira Rodrigues, Denise Carvalho Takenaka, Marcos Azevedo Benac

de períodos ao longo do ano. É o caso, por exemplo, de produtos voltados para os efeitos do clima, que têm maior volume de vendas durante o outono por conta das reduções bruscas na temperatura.

\subsubsection{Visibilidade}

A visibilidade, ou seja, o contato com o cliente, é baixo. Por ser uma distribuidora de medicamentos, o atendimento é feito através dos seus meios eletrônico, na qual, os seus colaboradores fazem o pedido e os recebem de acordo com a quantidade solicitada. Não há a necessidade, por parte dos clientes, acompanhar o processo de produtivo dos medicamentos, ou seja, a empresa de medicamentos os recebe prontos dos laboratórios e apenas os distribui.

\subsection{Processos logísticos da empresa (Layout)}

Destaca-se que o arranjo físico da empresa, conforme figura 4, é do tipo celular, pois mescla fatores característicos da produção e operação dentro de um mesmo ambiente. O processo de recebimento é organizado através de seus endereços de destino, podendo ser entre as duas áreas denominadas: pulmão e fixo. O pulmão é onde o estoque encontra-se paletizado (utilizamos pallet PBR e filme). $O$ fixo é onde o estoque possui caixas fechadas de produtos e não está paletizado. $O$ estoque do fixo atende à linha de produção (produção de pedidos), é dele que abastecemos a caixas bin do picking. Quando o estoque do fixo está por terminar, é reabastecido através da transferência de mercadorias do estoque do pulmão.

O processo de operação funciona de maneira eficiente através do sistema pick to light onde a facilidade de obter informações concisas se torna muito mais efetivo e seguro para a empresa. $O$ sistema ocorre através de displays luminosos que mostram em qual endereço o operador, que está fazendo a separação, deve pegar o produto, além de detalhar a quantidade desse produto. $O$ sistema pick to light é integrado ao WMS da empresa e recebe as informações de todos os pedidos a serem separados, o que ajuda na agilidade e redução erros do processo. 


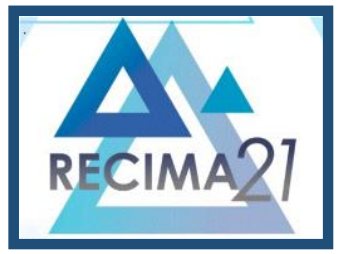

\section{RECIMA21 - REVISTA CIENTÍFICA MULTIDISCIPLINAR}

MODELO DE AVALIAC̄̃̃ DE MATURIDADE DA INDÚSTRIA 4.0 - ESTUDO DE CASO EM UM CENTRO DE DISTRIBUICCÃO DE MEDICAMENTOS NA BAIXADA FLUMINENSE/RJ

Jorge Luiz Machado, Mariana Gonçalves de Carvalho Wolff, Ariele Silva Moreira Rodrigues, Denise Carvalho Takenaka, Marcos Azevedo Benac

Figura 5 - Planta do layout da

organização

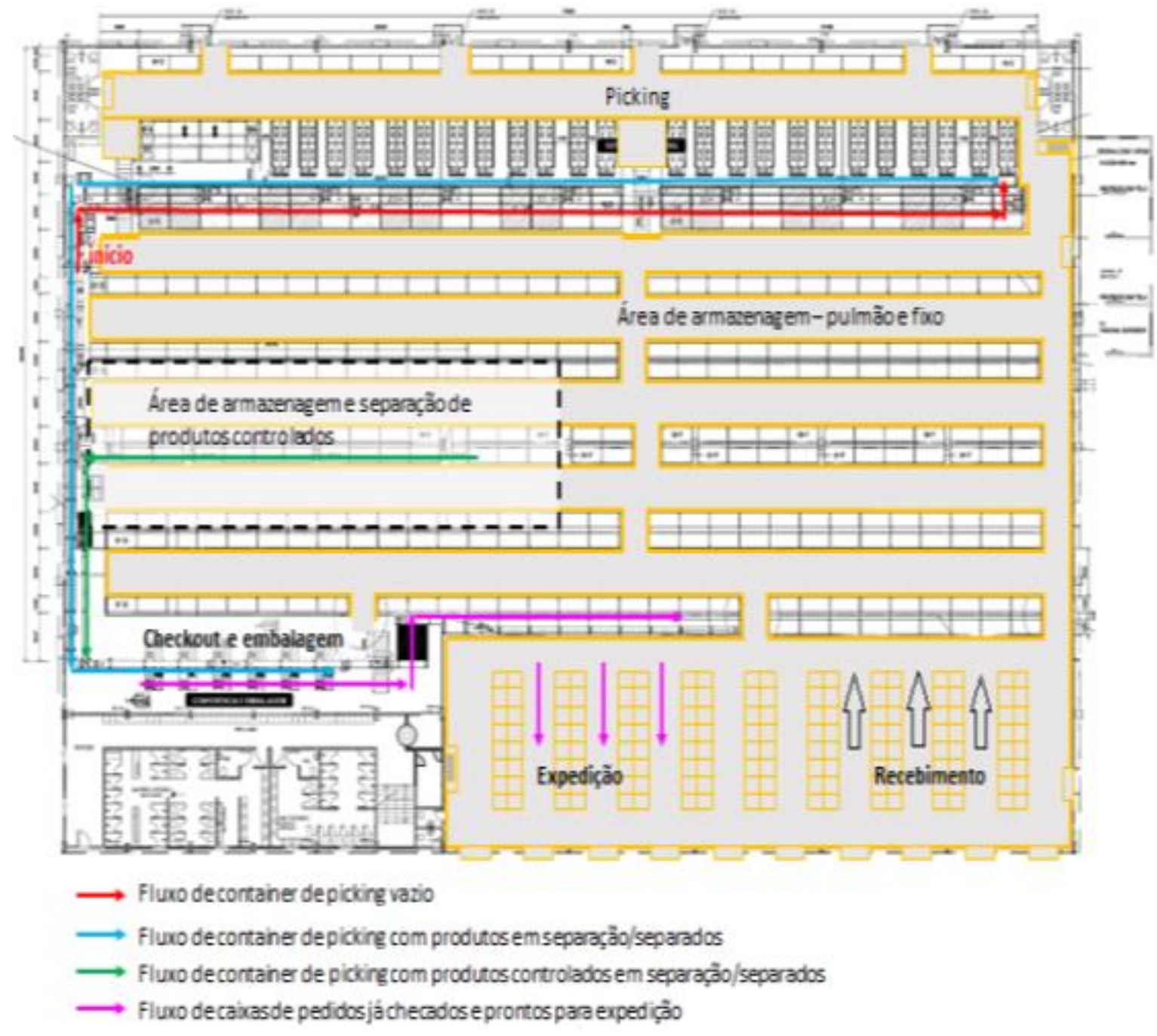

Fonte: Adaptado pelos autores (2020) de documentos originais da empresa.

\subsection{Descrição do processo de operação}

O atendimento ao público feito pela empresa de medicamentos se dá através da oferta de produtos tangíveis e prestação de serviço. Produtos tangíveis, porque compra os medicamentos dos laboratórios e faz uma triagem nos mesmos, revisando suas composições, fazendo o processo de separação e embalando, rotulando e armazenando de acordo com suas especificidades. Em relação aos serviços, o processo de operação se conceitua principalmente nos sistemas de controle de estocagem através de ferramentas como o pick to light que facilitam e agilizam todo o processo de envio aos clientes.

No que se refere a operação do negócio, ou seja, o serviço de distribuição, o início do processo de distribuição dar-se-á por meio da automatização do processo, ou seja, os pedidos feitos por site da empresa, software de pedidos com certificação digital (pedido eletrônico) e através do 


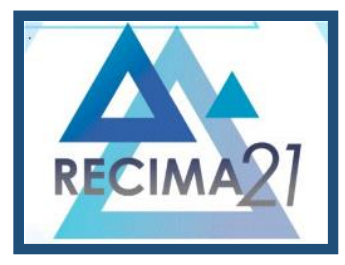

\section{RECIMA21 - REVISTA CIENTÍFICA MULTIDISCIPLINAR}

MODELO DE AVALIACÃO DE MATURIDADE DA INDÚSTRIA 4.0 - ESTUDO DE CASO EM UM CENTRO DE DISTRIBUIÇÃO DE MEDICAMENTOS NA BAIXADA FLUMINENSE/RJ Jorge Luiz Machado, Mariana Gonçalves de Carvalho Wolff, Ariele Silva Moreira Rodrigues, Denise Carvalho Takenaka, Marcos Azevedo Benac

SAC da empresa, gera após a confirmação de pagamento dos pedidos, um Picking ou Order Picking. O picking é a atividade responsável pela separação ou preparação de pedidos. Este termo é muito utilizado para definir o processo logístico de localização e coleta de produtos dentro do estoque.

Após toda etapa de separação dos produtos solicitados, os pedidos (endereços de destino) são encaminhados para área chamada de pulmão e fixo onde as caixas pin são numeradas e com códigos SKU's (Stock Keeping Unit - é uma "Unidade de Controle de Estoque" -, ou seja, um código de identificação única para seus produtos), referentes a quantidade de medicamentos solicitados. Estas caixas são enviadas automaticamente para área chamada de estação picking, onde rolam em esteiras automatizadas, que através de sensores em todo o percurso, param nas estações de coletas e, através da ação humana são abastecidas de acordo com as quantidades pedidas.

Completada com as quantidades dos produtos solicitados, o funcionário libera a caixa, apertando um botão picking to light, para que prossiga para próxima estação. Concluídas todas as estações, chega-se ao setor de Checkout. Sem que haja qualquer erro nas estações de coletas, fazse através do código de barra, a confirmação dos pedidos e os medicamentos são embalados e enviados manualmente para área de expedição. Neste momento ocorre nova leitura do código de barras, através da tecnologia RFID que envia as informações ao software ERP de gerenciamento. Um relatório sobre aquele lote de pedido é gerado e enviado à área da base de entrega. Após nova conferência dos pedidos o processo é finalizado e os lotes são embarcados em carretas de transportadoras terceirizadas. Todo o processo é gerido automaticamente pelos softwares ERP, MES e WMS, ou seja, a interoperabilidade (integração) dos softwares é que controla na linha de produção, diminuindo, consideravelmente, a margem de erro dos pedidos solicitados.

\subsection{Esboço do Estudo de caso}

O estudo visa aplicar o modelo de maturidade na empresa de distribuição de medicamentos, para a verificação da análise do nível de maturidade voltada para a Indústria 4.0. A análise foi realizada por meio de entrevistas informais, não gravadas, através da aplicação de questionários sobre maturidade, elaborado para o estudo de caso. São 41 questões, dividas em sete seções, sendo uma direcionada ao perfil profissiográfico dos respondentes e as demais voltadas para identificar as evidências de cada um dos atributos apresentados, como: estratégia e organização, fábrica inteligente, modelo digital de fábrica, operações inteligentes (integração vertical e horizontal, segurança de dados e comunicações e produtos de inteligentes), serviços orientados por dados e funcionários.

Complementando à aplicação do questionário, fez-se visitas ao $\mathrm{CD}$ da empresa de distribuição de medicamentos, para acompanhar in loco, a descrição do processo operacional, buscando alcançar um maior entendimento dos processos de distribuição de medicamentos e 


\title{
RECIMA21 - REVISTA CIENTÍFICA MULTIDISCIPLINAR
}

\author{
MODELO DE AVALIAC̄ÃO DE MATURIDADE DA INDÚSTRIA 4.0 - ESTUDO DE CASO \\ EM UM CENTRO DE DISTRIBUIÇÃO DE MEDICAMENTOS NA BAIXADA FLUMINENSE/RJ \\ Jorge Luiz Machado, Mariana Gonçalves de Carvalho Wolff, Ariele Silva Moreira Rodrigues, \\ Denise Carvalho Takenaka, Marcos Azevedo Benac
}

realizar uma análise mais acurada sobre a gestão de operações exercida, em especial, sobre as tecnologias em uso no processo operacional.

A empresa de distribuição de medicamentos é uma organização de grande porte do setor. Devido à mudança de localidade, O CD passou por um processo de reorganização produtiva concentrada em ferramentas de manufatura enxuta, Lean Manufacturing. Baseado nesta ferramenta, a escolha dessa empresa, deu-se porque o protótipo proposto para este TCC parte do axioma de que é necessário se ter um processo produtivo bastante organizado para que os princípios de manufatura avançada possam ser implementados, com o advento da Indústria 4.0.

Sendo uma distribuidora de medicamentos, a empresa compra dos laboratórios e tem seus processos produtivos sob demanda, através de pedidos dos clientes, ou seja, existe uma grande diversidade na separação dos produtos tangíveis. Portanto, este estudo caso, não selecionou um produto específico, para análise do processo.

\subsection{Dimensões para a Indústria 4.0}

Cada dimensão avaliada dirá se a empresa atende às necessidades da Indústria 4.0. Vale ressaltar que estas dimensões aqui relatadas são diferentes dos seis estágios de desenvolvimento do processo de transformação, relacionados no Guia de avaliação de maturidade da ACATECH.

As dimensões de maturidade são avaliadas de acordo com 5 níveis onde o nível 1 representa a completa falta de atributos que suportam os conceitos da Indústria 4.0, e o nível 5 representa 0 estado da arte dos atributos requeridos, descritos no Quadro 1 abaixo.

Quadro 2 - Itens de avaliação de maturidade propostos

\begin{tabular}{|c|c|}
\hline DIMENSÕES & ITENS DE AVALIAÇÃO DE MATURIDADE \\
\hline \multirow{6}{*}{$\begin{array}{c}\text { Estratégia } \\
\& \\
\text { Organização }\end{array}$} & Mapa estratégico para a implementação da Indústria 4.0 \\
\hline & Disponibilidade de recursos para a realização das ações \\
\hline & Adaptação do modelo de negócios existente para a Indústria 4.0 \\
\hline & Comunicação e documentação das atividades da Indústria 4.0 \\
\hline & Compatibilidade da Indústria 4.0 com a estratégia corporativa \\
\hline & Existência de estratégia para a transformação digital \\
\hline \multirow{3}{*}{$\begin{array}{l}\text { Fábrica } \\
\text { Inteligente }\end{array}$} & Sistemas de produção e logísticos se organizam amplamente sem intervenção humana \\
\hline & CPS que conectam os ambientes físico e virtual através de uma infraestrutura de TI. \\
\hline & $\begin{array}{l}\text { Requer a comunicação em tempo real entre empresas, sistemas de produção, de } \\
\text { informação e pessoas }\end{array}$ \\
\hline \multirow{2}{*}{$\begin{array}{l}\text { Operações } \\
\text { Inteligentes }\end{array}$} & Utilização de dados sobre os clientes e Digitalização das vendas e dos serviços. \\
\hline & Organização digital de informações de clientes \\
\hline \multirow[t]{5}{*}{$\begin{array}{c}\text { Produtos } \\
\text { Inteligentes }\end{array}$} & $\begin{array}{l}\text { Os produtos físicos são equipados com componentes de TIC (sensores, RFID, etc.) } \\
\text { Individualização de produtos }\end{array}$ \\
\hline & Individualização de produtos \\
\hline & Digitalização de produtos \\
\hline & Integração dos produtos em outros sistemas \\
\hline & Flexibilidade das características dos produtos \\
\hline \multirow{2}{*}{$\begin{array}{l}\text { Operações } \\
\text { Manufatura }\end{array}$} & Descentralização de processos, Modelagem e simulação, Interdisciplinaridade. \\
\hline & Colaboração interdepartamental \\
\hline
\end{tabular}




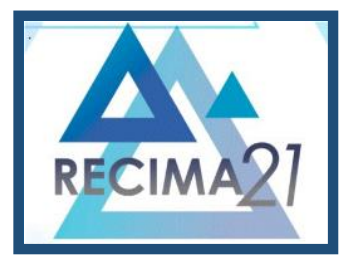

\section{RECIMA21 - REVISTA CIENTÍFICA MULTIDISCIPLINAR}

MODELO DE AVALIAÇÃO DE MATURIDADE DA INDÚSTRIA 4.0 - ESTUDO DE CASO EM UM CENTRO DE DISTRIBUIÇÃO DE MEDICAMENTOS NA BAIXADA FLUMINENSE/RJ

Jorge Luiz Machado, Mariana Gonçalves de Carvalho Wolff, Ariele Silva Moreira Rodrigues, Denise Carvalho Takenaka, Marcos Azevedo Benac

\begin{tabular}{|c|c|}
\hline \multirow{3}{*}{$\begin{array}{c}\text { Cultura } \\
\text { Organizacional }\end{array}$} & Compartilhamento do conhecimento \\
\hline & Abertura a inovação e colaboração entre empresas \\
\hline & Valor das tecnologias de informação e comunicação na empresa \\
\hline \multirow{3}{*}{$\begin{array}{c}\text { Funcionários } \\
\text { (colaboradores) }\end{array}$} & Competências dos colaboradores em tecnologias de informação e comunicação. \\
\hline & Abertura dos empregados para novas tecnologias \\
\hline & Treinamento e educação em instituições voltadas para áreas tecnológicas \\
\hline \multirow[t]{3}{*}{ Governança } & Regras trabalhistas para a Indústria 4.0 \\
\hline & Adequabilidade de padrões tecnológicos \\
\hline & Proteção de propriedade intelectual \\
\hline \multirow{3}{*}{$\begin{array}{l}\text { Tecnologia } \\
\text { Habilitadoras }\end{array}$} & Existências de modernas tecnologias de informação e comunicação \\
\hline & Utilização de dispositivos móveis \\
\hline & Utilização de comunicação máquina-máquina (M2M) \\
\hline
\end{tabular}

Fonte: O autor (2020), adaptado em Schumacher, Erol e Sihn (2016).

As avaliações são sintetizadas em um processo de três etapas, na qual, destacamos, a medição dos itens de maturidade nas empresas via questionários, que, segundo Schumacher, Erol e Sihn (2016) para a aplicação do questionário dentro das empresas, se faz necessário que o entrevistado possua um bom entendimento prévio dos conceitos da Indústria 4.0. A segunda etapa, refere-se ao cálculo do nível de maturidade nas nove dimensões, listada no Quadro 2, auxiliado por software Excel, através do fator de ponderação. Cada dimensão terá uma média ponderada dos resultados obtidos e cada item de avaliação será multiplicado pelo respectivo fator de ponderação, o peso. Quatro dessas dimensões tem peso um e as dimensões relacionadas às áreas tecnológicas recebem peso dois. A última etapa compreende a representação visual do nível de maturidade via relatórios de maturidade e gráfico radar.

\subsection{Resultados da pesquisa}

Os resultados apresentados não avaliam o desempenho do processo de produção da empresa e nem vaticina indicações de melhorias de maturidade, mas analisam o estágio atual da empresa em relação aos conceitos da Indústria 4.0. De acordo com Bruin et al. (2005):

Um modelo de maturidade descritivo pode ser entendido como um modelo que serve para avaliar a maturidade "como ela é", ou seja, descreve a maturidade em sua situação atual, e não prevê indicações de melhorias de maturidade nem relaciona o resultado com a performance da empresa (BRUIN, et al., 2005, apud SANTOS, 2018, p.56).

\subsubsection{Análise dos dados}

O questionário de maturidade elaborado através da coleta de dados faz-se necessário mensurar o índice de maturidade levando em consideração as seis dimensões escolhidas para o modelo. O posicionamento da empresa estará em um dos seis níveis de maturidades para indústria 4.0:

- Nível 1 - Organização; 


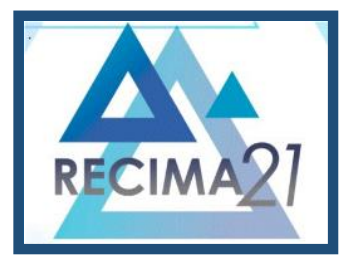

\section{RECIMA21 - REVISTA CIENTÍFICA MULTIDISCIPLINAR}

MODELO DE AVALIAÇ̃̃O DE MATURIDADE DA INDÚSTRIA 4.0 - ESTUDO DE CASO EM UM CENTRO DE DISTRIBUIÇÃO DE MEDICAMENTOS NA BAIXADA FLUMINENSE/RJ Jorge Luiz Machado, Mariana Gonçalves de Carvalho Wolff, Ariele Silva Moreira Rodrigues, Denise Carvalho Takenaka, Marcos Azevedo Benac

- Nível 2 - Conectividade;

- Nível 3 - Visibilidade;

- Nível 4 - Gestão guiada por dados (capacitação);

- Nível 5 - Simulação e predição;

- Nível 6 - Automação;

Para a pontuação das respostas em cada dimensão foi utilizada uma a escala de zero a cinco. Zero representa que nenhum requisito foi cumprido, um possui baixa importância, dois pouco importante, três moderadamente importante, quatro muito importante e cinco extremamente importante em relação ao cenário ideal de Indústria 4.0. A empresa apresenta evidências de que atende os requisitos definidos na proposta de adaptação do modelo de maturidade industrial. Ressalta-se que a pontuação se deu por meio das principais evidências coletadas para cada uma das dimensões, sendo que as voltadas para as tecnologias serão o foco desse trabalho.

\subsubsection{Dimensão Funcionários}

Para Lichtblau et al. (2015, apud Da Silva, 2019), com o avanço tecnológico, através da transformação digital nas organizações, os funcionários (colaboradores), precisam buscar novas habilidades e qualificações e as empresas necessitarão investir em treinamento e educação continuada. As pessoas são quem movem uma organização e, se bem treinados e qualificados, se tornam o grande diferencial do negócio, apesar das tecnologias inovadoras. Na dimensão funcionários as perguntas foram organizadas para avaliar a qualificação dos funcionários, tais como: i) Importância do tema "Indústria 4.0", ii) Treinamento e educação em instituições voltadas para áreas tecnológicas; iii) Abertura dos empregados para novas tecnologias; iv) Competências técnicas habilidade com segurança em Tl; v) Competências pessoas (flexibilidade, motivação, mudança, inteligência emocional, Mentalidade digital), conforme exemplo da Tabela 1, abaixo.

Tabela 1 - Funcionários

\begin{tabular}{|c|c|c|c|}
\hline DIMENSÄO - FUNCIONARIOS & Nível & Média & Perffl* ${ }^{\star}$ \\
\hline Importância do tema "Indústria 4.0" & 4 & \multirow{5}{*}{1,6} & \multirow{5}{*}{$\begin{array}{l}\text { Pouco } \\
\text { Importante }\end{array}$} \\
\hline Treinamento e convênios com Instituições de educação voltadas para área de TI. & 0 & & \\
\hline Abertura dos empregados para as novas tecnologias & 0 & & \\
\hline Competências técnicas: Habilidade com segurança em TI & 2 & & \\
\hline $\begin{array}{l}\text { Competências pessoais (flexibilidade, motivação, mudança, inteligência } \\
\text { emocional, Mentalidade digital) }\end{array}$ & 2 & & \\
\hline
\end{tabular}

Fonte: Elaborado pelos autores, baseado em Silva e Rocha (2019). 


\section{RECIMA21 - REVISTA CIENTÍFICA MULTIDISCIPLINAR}

MODELO DE AVALIAÇ̃̃O DE MATURIDADE DA INDÚSTRIA 4.0 - ESTUDO DE CASO EM UM CENTRO DE DISTRIBUIČ̃̃O DE MEDICAMENTOS NA BAIXADA FLUMINENSE/RJ

Jorge Luiz Machado, Mariana Gonçalves de Carvalho Wolff, Ariele Silva Moreira Rodrigues, Denise Carvalho Takenaka, Marcos Azevedo Benac

\subsubsection{Dimensão estratégia e organização}

O modelo de "Indústria 4.0", além do uso de tecnologia digital, buscar oferecer novos modelos de negócios, com o objetivo de aumentar a produtividade e competitividade. Na dimensão de estratégia e organização, foram analisados cinco critérios: i) investimentos nos últimos dois anos; ii) Nível de investimento em áreas (logística, TI, P\&D, compras, vendas, serviços, produção/manufatura), para os próximos 5 anos; iii) Estratégia em desenvolvimento (inciativa piloto); iv) sistema de indicadores que orienta a empresa para à Indústria 4.0; v) Nível de envolvimento do setor estratégico (Presidente, CEO e Direção). Conforme exemplo da Tabela 2 abaixo.

Tabela 2 - Estratégia e Organização

\begin{tabular}{|c|c|c|c|}
\hline DIMENSĀO - ESTRATEGIA \& ORGANIZAÇĀO & Nível & Média & Perfil* \\
\hline $\begin{array}{l}\text { Receberam médio investimento: Logística, P\&D, Produção. As demais } \\
\text { receberam pouco investimento, nos últimos } 2 \text { anos }\end{array}$ & 1 & \multirow{5}{*}{1,4} & \multirow{5}{*}{$\begin{array}{c}\text { Baixa } \\
\text { importância }\end{array}$} \\
\hline $\begin{array}{l}\text { Nível de investimento em áreas (Logística, TI, P\&D, compras, vendas, } \\
\text { serviços, produção/manufatura), para os próximos } 5 \text { anos }\end{array}$ & 1 & & \\
\hline Nível de envolvimento do setor estratégico (Presidente- CEO e Direção). & 4 & & \\
\hline Não temos um sistema de indicadores que nos dê alguma orientação. & 0 & & \\
\hline Estratégia em Desenvolvimento (inciativa piloto) & 1 & & \\
\hline
\end{tabular}

Fonte: Elaborado pelos autores, baseado em Silva e Rocha (2019).

\subsubsection{Dimensão Fábrica Inteligente}

De acordo com Silva e Rocha (2019): "Uma Fl é um ambiente de produção em que os sistemas de produção e logísticos se organizam amplamente sem intervenção humana." Para os autores, é através de uma infraestrutura de TI, como, por exemplo, a internet das coisas (IoT), que os sistemas CPS se conectam ao ambiente físico e virtual. Para tanto, dez critérios foram analisados, a fim de medir a dimensão fábrica inteligentes: i) automação digital com sensores para controle do processo, com intervenção humana; ii) monitoramento e controle remoto da cadeia de valor, com sistemas ERP, MES e WMS, utilizados com interface com o sistema central; iii) convergência dos sistemas como WMS, ERP e MES; iv) "Internet das coisas" - incorporação de serviços digitais na logística do produto; v) coleta dados durante a produção; vi) percentual dos dados coletados; vii) utilização dos dados coletados; vii) produto guiado automaticamente na linha de produção e, ix) funcionalidades dos seus equipamentos como interoperabilidade - integração e colaboração com outras máquinas/sistemas possíveis e; $x$ ) se utiliza I.A e nuvem digital. Conforme exemplo da Tabela 3 abaixo.

Tabela 3 - Fábrica inteligente

\begin{tabular}{c|c|c|c}
\hline DIMENSÃO - FÁBRICA INTELIGENTE & Nível & $\begin{array}{c}\text { Média } \\
\text { peso 2 }\end{array}$ & Perfi|* $^{*}$ \\
\hline Automação digital com sensores para controle do processo, com & 1 & & \\
\hline
\end{tabular}




\section{RECIMA21 - REVISTA CIENTÍFICA MULTIDISCIPLINAR}

MODELO DE AVALIAÇÃO DE MATURIDADE DA INDÚSTRIA 4.0 - ESTUDO DE CASO EM UM CENTRO DE DISTRIBUIÇÃO DE MEDICAMENTOS NA BAIXADA FLUMINENSE/RJ Jorge Luiz Machado, Mariana Gonçalves de Carvalho Wolff, Ariele Silva Moreira Rodrigues, Denise Carvalho Takenaka, Marcos Azevedo Benac

\begin{tabular}{|c|c|c|c|}
\hline intervenção humana. & & \multirow{10}{*}{2,1} & \multirow{10}{*}{$\begin{array}{l}\text { Pouco } \\
\text { importante }\end{array}$} \\
\hline $\begin{array}{l}\text { Controle remoto da produção o com sistemas ERP, MES e WMS, } \\
\text { utilizados com interface com o sistema central. }\end{array}$ & 4 & & \\
\hline Convergência dos sistemas como WMS, ERP e MES. & 5 & & \\
\hline loT - incorporação de serviços digitais na logística do produto. & 1 & & \\
\hline Coleta os dados durante a produção. & 3 & & \\
\hline $\begin{array}{l}\text { Os dados coletados diretamente dos sistemas de informação } \\
\text { corporativos, não usa I.A e nem nuvem digital. }\end{array}$ & 1 & & \\
\hline $\begin{array}{l}\text { Os dados coletados utilizados em: otimizização de processos logísticos, } \\
\text { gestão da qualidade e controle da produção. }\end{array}$ & 1 & & \\
\hline $\begin{array}{l}\text { Funcionalidade dos seus equipamentos como a interoperabilidade e } \\
\text { M2M. }\end{array}$ & 1 & & \\
\hline Acima de $50 \%$ é o percentual dos dados coletados são utilizados. & 4 & & \\
\hline Não possui modelagem digital & 0 & & \\
\hline
\end{tabular}

Fonte: Elaborado pelos autores, baseado em Silva e Rocha (2019).

\subsubsection{Dimensão Operações inteligentes}

Os sistemas de planejamento da produção, bem como, o gerenciamento da cadeia de suprimentos, têm abordagens inteiramente novas, graças ao advento da digitalização. Silva e Rocha (2019) definem como operações inteligentes, os requisitos técnicos necessários para o gerenciamento da cadeia de suprimentos, realizarem o autocontrole dos produtos, aumentando a produtividade, qualidade e flexibilidade. Utilizaremos cinco critérios para determinarmos essa dimensão, tais como: i) Aplicabilidade da I 4.0; ii) segunrança da informação para as redes e sistemas na logística; iii) serviços de nuvem, Cloud computing; iv) compartilhamento de informação com os colaboradores externos e; v) segurança em TI. A Tabela 4, abaixo consolida esses critérios e suas respectivas notas.

Tabela 4 - Operações inteligentes

\begin{tabular}{|c|c|c|c|}
\hline DIMENSĀO - OPERAÇŌES INTELIGENTES & Nível & Média & Perfil $^{*}$ \\
\hline $\begin{array}{l}\text { Aplicabilidade da I } 4.0 \text { - o produto é guiado autonomamente linha de } \\
\text { produção. }\end{array}$ & 4 & \multirow{5}{*}{2,4} & \multirow{5}{*}{$\begin{array}{l}\text { Pouco } \\
\text { importante }\end{array}$} \\
\hline $\begin{array}{l}\text { Importância da segurança da informação para as redes e sistemas na } \\
\text { logística. }\end{array}$ & 4 & & \\
\hline $\begin{array}{l}\text { Não possui compartilhamento de informação com os colaboradores } \\
\text { externos }\end{array}$ & 0 & & \\
\hline Importância de ferramenta de Ciber-segurança & 4 & & \\
\hline Utiliza serviços de nuvem - Cloud computing & 0 & & \\
\hline \multicolumn{4}{|l|}{ *Soma dos níveis $/ 5=$ média aproximada } \\
\hline
\end{tabular}

Fonte: Elaborado pelos autores, baseado em Silva e Rocha (2019).

\subsubsection{Dimensão Produtos inteligentes}

Conforme descrito no tópico 4.4 que trata da descrição do processo de operação, a preparação para entrega dos produtos é feita através da tecnologia RFID, com o auxílio de um software ERP de gerenciamento. Toda linha de produção é gerida automaticamente pelos softwares 


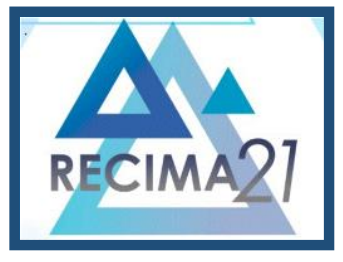

\section{RECIMA21 - REVISTA CIENTÍFICA MULTIDISCIPLINAR}

MODELO DE AVALIAÇÃO DE MATURIDADE DA INDÚSTRIA 4.0 - ESTUDO DE CASO EM UM CENTRO DE DISTRIBUIÇÃO DE MEDICAMENTOS NA BAIXADA FLUMINENSE/RJ Jorge Luiz Machado, Mariana Gonçalves de Carvalho Wolff, Ariele Silva Moreira Rodrigues, Denise Carvalho Takenaka, Marcos Azevedo Benac

ERP, MES e WMS, que diminuem consideravelmente a margem de erro em todo o processo, tornando assim, uma produção automatizada, flexível e eficiente. Cinco critérios serão utilizados para esta dimensão, como: i) utilização dos usos de dados; ii) diagnósticos de causas de falhas; iii) manutenção preditiva; iv) manutenção prescritivas e; v) condição do produto, ambiente e operações.

A Tabela 4 abaixo resume os níveis da organização.

Tabela 5 - Produtos inteligentes

\begin{tabular}{|c|c|c|c|}
\hline DIMENSÄO - PRODUTOS INTELIGENTES & Nivel & Média & Perfil ${ }^{\star}$ \\
\hline Acima de $50 \%$ dos dados coletados são utilizados & 4 & \multirow{5}{*}{3,0} & \multirow{5}{*}{$\begin{array}{l}\text { Moderadamente } \\
\text { Importante }\end{array}$} \\
\hline Causas de falhas - entre $51 \%$ a $75 \%$ & 4 & & \\
\hline $\begin{array}{l}\text { Captura de dados das condições do produto, ambiente e operações } \\
\text { (entre } 26 \% \text { e } 50 \% \text { ) }\end{array}$ & 3 & & \\
\hline Manutenção prescritiva - menos de $25 \%$ & 2 & & \\
\hline Manutenção preditiva - menos de $25 \%$ & 2 & & \\
\hline
\end{tabular}

Fonte: Elaborado pelos autores, baseado em Silva e Rocha (2019).

\subsubsection{Dimensão Tecnologias Habilitadoras}

Conforme visto anteriormente, Venturelli (2019) divide as tecnologias habilitadoras das empresas e as transformam em digital, condição essencial para aplicabilidade do conceito de Indústria 4.0, em três estágios: os pré-requisitos que compreendem a automação, otimização e convergência; a digitalização básica por último as tecnologias habilitadoras. Para analisar estes dados, vamos seguir os critérios apresentados pelo autor. São usados dezessete critérios para essa dimensão, divididos em três fases: automação, otimização e convergência (pré-requisitos); IoT, Cibersegurança, Cloud Computing e big data (Digitalização básica) e; IloT, I.A Machine Leaning, Mineração de dados, realidade virtual, impressão 3D, prototipação de digital (gêmeos digitais), AGV, blockchain, geolocalização e rede Wireless (5G). A Tabela 6, abaixo consolida os critérios.

Tabela 6 - Tecnologias Habilitadoras

\begin{tabular}{|c|c|c|c|c|}
\hline $\begin{array}{l}\text { Tecnologias } \\
\text { Habilitadoras }\end{array}$ & Critérios da dimensão & Nível & $\begin{array}{l}\text { Média } \\
\text { Peso } 2\end{array}$ & Perfil** \\
\hline \multirow{3}{*}{ Pré-requisitos } & Possui automação em toda a cadeia de valor & 4 & \multirow[b]{3}{*}{4,0} & \multirow{3}{*}{$\begin{array}{c}\text { Muito } \\
\text { Importante }\end{array}$} \\
\hline & Possui otimização em toda a cadeia de valor & 4 & & \\
\hline & Possui convergência em toda a cadeia valor & 4 & & \\
\hline \multirow{4}{*}{$\begin{array}{c}\text { Digitalização } \\
\text { Básica }\end{array}$} & Utiliza a IoT em toda a cadeia de valor & 4 & \multirow{4}{*}{3,0} & \multirow{4}{*}{$\begin{array}{c}\text { Moderada } \\
\text { mente } \\
\text { Importante }\end{array}$} \\
\hline & Utiliza ciber segurança em toda a cadeia de valor & 4 & & \\
\hline & $\begin{array}{l}\text { Utiliza Cloud Computing em toda a cadeia de } \\
\text { valor }\end{array}$ & 0 & & \\
\hline & Utiliza Big data em toda a cadeia de valor & 4 & & \\
\hline \multirow[b]{3}{*}{ Transformação } & $\begin{array}{l}\text { Utiliza a IloT (Internet industrial) em toda a cadeia } \\
\text { de valor }\end{array}$ & 2 & & \\
\hline & $\begin{array}{l}\text { Utiliza a I.A (Inteligência artificial) em toda a } \\
\text { cadeia de valor }\end{array}$ & 0 & & \\
\hline & $\begin{array}{l}\text { Utiliza a Mining Dado (mineração de dados) em } \\
\text { toda a cadeia de valor }\end{array}$ & 2 & & \\
\hline
\end{tabular}




\section{RECIMA21 - REVISTA CIENTÍFICA MULTIDISCIPLINAR}

MODELO DE AVALIAÇ̃̃O DE MATURIDADE DA INDÚSTRIA 4.0 - ESTUDO DE CASO EM UM CENTRO DE DISTRIBUICCÃO DE MEDICAMENTOS NA BAIXADA FLUMINENSE/RJ

Jorge Luiz Machado, Mariana Gonçalves de Carvalho Wolff, Ariele Silva Moreira Rodrigues, Denise Carvalho Takenaka, Marcos Azevedo Benac

\begin{tabular}{|c|c|c|c|c|}
\hline \multirow[t]{7}{*}{ Digital } & Utiliza Realidade virtual em toda a cadeia de valor & 0 & \multirow{7}{*}{$1,5^{\star}$} & \multirow{7}{*}{$\begin{array}{c}\text { Moderada } \\
\text { mente } \\
\text { Importante }\end{array}$} \\
\hline & Utiliza a impressão $3 D$ em toda a cadeia de valor & 2 & & \\
\hline & $\begin{array}{l}\text { Usa o blockchain (protocolo de segurança), no } \\
\text { relacionamento com os colaboradores }\end{array}$ & 4 & & \\
\hline & $\begin{array}{l}\text { Utiliza Rede Wireless (4 G ou } 5 G \text { ) em toda a } \\
\text { cadeia de valor }\end{array}$ & 2 & & \\
\hline & Utiliza a $A G V$ na linha de produção & 0 & & \\
\hline & $\begin{array}{l}\text { Usa sistema de Geolocalização na logística de } \\
\text { transporte }\end{array}$ & 1 & & \\
\hline & Usa RFDI, em toda a cadeia logística & 2 & & \\
\hline
\end{tabular}

Fonte: Elaborado pelos autores, baseado em Silva e Rocha (2019).

O Gráfico 1 abaixo consolida o nível de maturidade da empresa avaliada, na escala de 1 a 5.

Gráfico 1 - Nível de Maturidade da Indústria 4.0 da Empresa Distribuidora por dimensões.

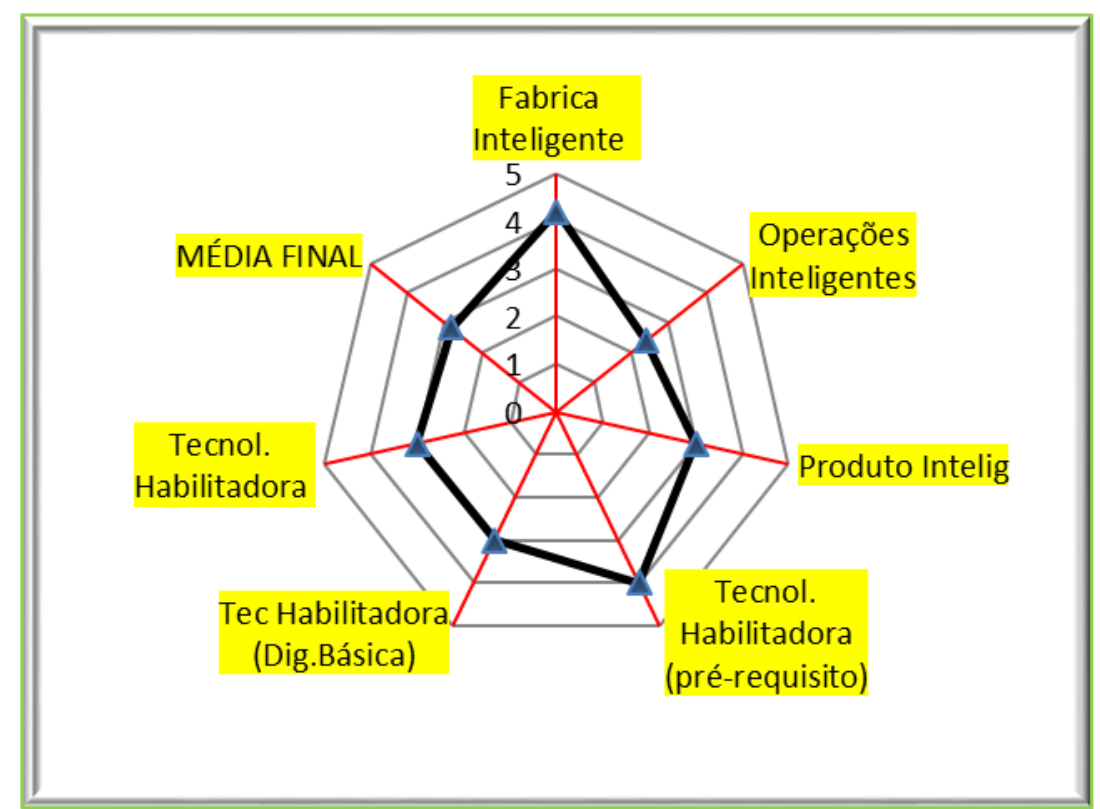

Fonte: Elaborado pelos autores (2020), a partir de dados da pesquisa de campo. 


\section{RECIMA21 - REVISTA CIENTÍFICA MULTIDISCIPLINAR}

MODELO DE AVALIAÇ̃̃O DE MATURIDADE DA INDÚSTRIA 4.0 - ESTUDO DE CASO EM UM CENTRO DE DISTRIBUIČ̃̃O DE MEDICAMENTOS NA BAIXADA FLUMINENSE/RJ

Jorge Luiz Machado, Mariana Gonçalves de Carvalho Wolff, Ariele Silva Moreira Rodrigues, Denise Carvalho Takenaka, Marcos Azevedo Benac

Os valores médios de cada dimensão constituem o cálculo para a obtenção do resultado da empresa, possibilitando sua análise quanto ao nível de maturidade da Indústria 4.0, conforme Tabela 7 abaixo.

Tabela 7. Resultado da empresa distribuidora de medicamentos-Nível de Maturidade.

\begin{tabular}{|c|c|c|c|}
\hline DIMENSÃO & Nível & Média & Perfil** \\
\hline Funcionários & 1,6 & \multirow{8}{*}{2,8} & \multirow{8}{*}{$\begin{array}{c}\text { Nível } 2 \\
\text { Conectividade }\end{array}$} \\
\hline Estratégia e Organização & 1,4 & & \\
\hline Fábrica Inteligente & 4,2 & & \\
\hline Operações Inteligentes & 2,4 & & \\
\hline Produtos Inteligentes & 3,0 & & \\
\hline Tecnologias habilitadoras - Pré-requisitos & 4,0 & & \\
\hline Tecnologias habilitadoras - Digitalização básica & 3,0 & & \\
\hline Tecnologias habilitadoras - Transformação digital & 3,0 & & \\
\hline \multicolumn{4}{|c|}{${ }^{*}$ Soma das dimensões / 5 = média aproximada } \\
\hline
\end{tabular}

Fonte: Elaborado pelos autores, baseado em Silva e Rocha (2019).

A empresa apresenta um nível 3 (três) de maturidade, denominado como conectividade, que se caracteriza por estar desenvolvendo uma estratégia para implementar os conceitos da Indústria 4.0. Neste nível parte dos sistemas operacionais permitem a conectividade e interoperabilidade, sendo os sistemas de negócios informatizados, atualizados ou substituídos por sistemas conectados. Entretanto, neste estágio a integração completa dos sistemas de informação e sistemas de operação ainda não estão totalmente implantadas. As informações coletadas pelos questionários mostram que a empresa investiu economicamente, nos últimos dois anos, mais em área da logística do que em TI.

Em alguns setores da linha de produção, os dados são coletados automaticamente, porém, no final da linha, a intervenção humana acontece e a infraestrutura dos equipamentos não satisfaz todos os requisitos para expansão futura. Outro fator importante é que estão sendo dados os primeiros passos para o compartilhamento das informações, tanto nos departamentos da empresa como com os parceiros de negócios.

No que concerne à segurança de $\mathrm{Tl}$ as soluções são adequadas, pois todos os acessos externos pelos colaboradores e clientes só é permitida através de um cadastro prévio e certificação digital. Outro exemplo de segurança é que não é permitido o acesso aos e-mails a partir de conexões externas, ou seja, o firewall bloqueia qualquer tentativa de comunicação com a internet.

Foi identificada a falta de convênios com instituições de ensino na área de $\mathrm{TI}$, não incentivando o treinamento dos funcionários do nível operacional. Faltam habilidades necessárias para a expansão da Indústria 4.0. Outro fator identificado é a falta de manutenção preventiva nas esteiras automatizadas. Não há coleta de dados pelas máquinas e, por isso, faltam evidências sobre manutenção deste equipamento. 


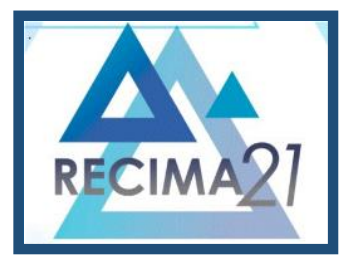

\section{RECIMA21 - REVISTA CIENTÍFICA MULTIDISCIPLINAR}

MODELO DE AVALIAÇ̃̃O DE MATURIDADE DA INDÚSTRIA 4.0 - ESTUDO DE CASO EM UM CENTRO DE DISTRIBUIÇÃO DE MEDICAMENTOS NA BAIXADA FLUMINENSE/RJ Jorge Luiz Machado, Mariana Gonçalves de Carvalho Wolff, Ariele Silva Moreira Rodrigues, Denise Carvalho Takenaka, Marcos Azevedo Benac

Diante do exposto neste tópico, é possível enquadrar a organização em um nível de maturidade, segundo os critérios do guia de avaliação de maturidade da $A C A T E C H$ e propor medidas necessárias para que a mesma evolua na implantação da Indústria 4.0.

\section{CONSIDERAÇÕES FINAIS}

Segundo o Senai (2018), a empresa estudada está com nível de maturidade intermediário dentro das características das empresas nacionais, ou seja, está caminhando para a implantação da Indústria 4.0. A organização está se preparando para a transição do estágio de organização para o de digitalização do processo de manufatura, correspondente ao nível 2, de conectividade.

De acordo com o que foi pesquisado o resultado final deste estudo é empírico e atende aos objetivos propostos. O trabalho desenvolve um modelo de maturidade, comparado com artigo publicado pelo SENAI e disponibilizado pela agência $\mathrm{CNI}$, que avalia o estágio das empresas no uso de tecnologias 4.0, através de teste online gratuito e presencial para medir a maturidade no uso de tecnologias habilitadoras. O presente estudo está em consonância com este órgão.

Dos 416 representantes de 15 segmentos respondentes, a maioria encontra-se nos dois primeiros estágios da Indústria 4.0 com uma nota média de 2,45 (SENAI, 2018). A empresa estudada está classificada no nível 2, segundo o teste de maturidade proposto e baseado no modelo desenvolvido pela Academia Nacional de Ciência e Engenharia $(A C A T E C H)$. Este nível é denominado conectividade porque implementa métodos de manufatura enxuta e utilizam sensores para coletar informações em tempo real, conectando a produção à sistemas de gerenciamento de produção, através dos softwares, como o ERP, WMS e MES.

O modelo propõe nove dimensões de análises. Na dimensão dos colaboradores mostra que implementar o conceito de Indústria 4.0 requer uma visão holística, aberta, dos responsáveis pelo nível estratégico da empresa. Também busca desenvolver, através de convênios com instituições de ensino voltadas para a área de TI, uma cultura digital no nível operacional.

$\mathrm{Na}$ dimensão estratégia e organização, verifica-se que os investimentos nos últimos dois anos em TI foram menores do que os aplicados em logística e que a previsão de investimento para os próximos cinco anos, será abaixo do esperado para esta área. Apesar do nível de envolvimento do setor estratégico (Presidente, CEO e Direção) ser considerado muito importante, na prática, questionam o retorno financeiro para a empresa, com a implementação da Indústria 4.0. Uma visão mais abrangente sobre o tema inclui uma nova orientação estratégica, o desenvolvimento de novas competências da força de trabalho, a adaptação dos modelos de negócio pelo desenvolvimento de novos produtos e serviços com novas funcionalidades customizadas, além da implementação das tecnologias habilitadoras. 


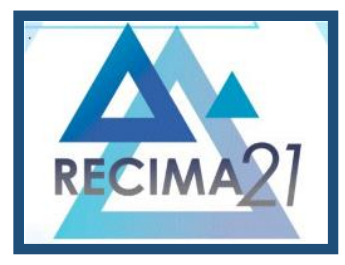

\section{RECIMA21 - REVISTA CIENTÍFICA MULTIDISCIPLINAR}

MODELO DE AVALIACÃO DE MATURIDADE DA INDÚSTRIA 4.0 - ESTUDO DE CASO EM UM CENTRO DE DISTRIBUIÇÃO DE MEDICAMENTOS NA BAIXADA FLUMINENSE/RJ Jorge Luiz Machado, Mariana Gonçalves de Carvalho Wolff, Ariele Silva Moreira Rodrigues, Denise Carvalho Takenaka, Marcos Azevedo Benac

No que se refere à dimensão fábrica, produto e operações inteligentes, o resultado alcançado é muito relevante para aplicação do conceito de Indústria 4.0, pois toda linha de produção é controlada por softwares, o que torna o processo produtivo automatizado, flexível e eficiente. Entretanto, observar-se que há intervenção humana durante o processo produtivo, contrariando Silva e Rocha (2019), sobre definição de fábricas inteligentes e compartilhamento dos dados em Cloud Computing (nuvem) com os colaboradores externos, ou stakeholders.

As tecnologias habilitadoras, divididas em três estágios, segundo Venturelli (2019), mostram que a empresa está mais bem-conceituada nas etapas do pré-requisito e digitalização básica. Automatização, otimização e convergência estão presentes em toda a linha de produção, bem como a utilização da ciber-segurança, internet das coisas (loT) e big data.

Dado o exposto, o modelo de maturidade aplicado na empresa é simples e fácil. O mesmo é aplicável a diversos setores industriais e em empresas de variados portes, proporcionando-lhes dados para o processo de tomada de decisão da empresa. Além de avaliar a maturidade atual da empresa, o modelo também ajuda no planejamento e definição da maturidade desejada, em relação às novas tendências tecnológicas decorrentes da quarta revolução industrial, identificando quais mudanças devem ocorrer para que a organização avance nos níveis de classificação.

Para um entendimento mais abrangente relacionado à pesquisa desenvolvida, sugere-se como trabalhos futuros uma análise mais ampla do tema Indústria 4.0, pois, há necessidade de se estender a aplicação do modelo de maturidade em grandes, médias e pequenas empresas da região da Baixada Fluminense. O intuito é buscar a transformação digital dessas empresas para que, através dessa mutação, gere vantagem competitiva, no cenário da indústria nacional. Para isso, o papel dos atores governamentais, como os municipais, estadual e federal deve propiciar fomentos ao crescimento dessas indústrias, por meio de incentivos fiscais para aquisição de tecnologias de ponta e consequente modernização das mesmas.

Devido às restrições impostas pela pandemia de Covid-19, os funcionários do nível operacional, um grupo importante na organização estudada, não puderam ser observadas. Portanto para uma melhor compreensão do assunto é recomendável, em futuros estudos sobre o tema, aplicar questionário aos colaboradores de empresas da região da Baixada Fluminense, buscando uma visão real do conhecimento desses envolvidos sobre o conceito de Industria 4.0 e suas tecnologias habilitadoras.

Outra sugestão para o desenvolvimento de estudos futuros é comparar duas empresas da Baixada Fluminense, que atuem em nicho de mercados diferentes. Dessa forma será possível comparar o desenvolvimento do conceito de Indústria 4.0 na região e propor melhorias conjuntas com a aplicação do modelo de forma qualitativa ou quantitativa, a fim de possibilitar inferências e conclusões que não foram vistos neste estudo. 
MODELO DE AVALIAÇÃO DE MATURIDADE DA INDÚSTRIA 4.0 - ESTUDO DE CASO EM UM CENTRO DE DISTRIBUIÇÃO DE MEDICAMENTOS NA BAIXADA FLUMINENSE/RJ Jorge Luiz Machado, Mariana Gonçalves de Carvalho Wolff, Ariele Silva Moreira Rodrigues, Denise Carvalho Takenaka, Marcos Azevedo Benac

\section{REFERÊNCIAS}

BRASIL. Serviço Nacional de Aprendizagem Industrial (SENAI). SENAI avalia estágio das empresas no uso de tecnologias 4.0. Agência CNI de Notícias. São Paulo: Portal da Industria, 2018. Disponível em: www.noticia.portaldaindustria.com.br. Acesso em: 01 maio 2020.

BRASIL. Ministério da saúde. Modelo de termo de consentimento livre e esclarecido -TCLE baseado nas diretrizes contidas na resolução CNS n466/2012. Disponível em: www.gov.br. Acesso em: 10 jul. 2020.

BRASIL. Ministério da saúde. Cartilha do participante em pesquisa. Disponível em: http://conselho.saude.gov.br/. Acesso em 14 jul. 2020.

CIRERA, Xaviern, MALONEY, William F. The innovation paradox: Developing-country capabilities and the unrealized promise of technological catch-up. The World Bank, 2017. Disponível em: https://elibrary.worldbank.org/doi/abs/10.1596/978-1-4648-1160-9. Acesso em: 17 ago. 2020.

COELHO, Pedro Miguel Nogueira. Rumo à Indústria 4.0. 2016. Dissertação (Mestrado) - Faculdade de Ciência e Tecnologia, Universidade de Coimbra - Coimbra - Portugal, 2016. Disponível em: https://estudogeral.uc.pt/. Acesso em: 02 maio 2020.

CONFEDERAÇÃO NACIONAL DA INDÚSTRIA. Indicadores de Competitividade da Indústria. 2015. Disponível em: www.portaldaindustria.com.br. Acesso em: 05 maio 2020.

CONFEDERAÇÃO NACIONAL DA INDÚSTRIA. Produtividade Brasileira é a que menos cresce em relação $\quad$ a 11 países. 2015.20 Disponível http://www.portaldaindustria.com.br/agenciacni/noticias/2015/02/produtividade-brasileira-e-a-quemenos-cresce-em-relacao-a-11-paises/. Acesso em: 05 maio 2020.

COSTA, Paulo Robson Melo. Princípios e Cenários da Indústria 4.0: Uma Revisão de Literatura. IX Congresso de Engenharia de Produção, Ponta Grossa, 2019 Disponível em: http://aprepro.org.br/portal/. Acesso em: 07 jul. 2020.

DIAS, Rita de Cássia Barros. Método Delphi: uma descrição de seus principais conceitos e características. 2007. (Monografia) - Faculdade de Ciência e Tecnologia, Universidade de São Paulo, São Paulo, 2007. Disponível em: http://www2.eca.usp.br/. Acesso em: 07 maio 2020.

FREITAS, Matheus Menna Barreto Cardoso de; FRAGA, Manoela Adriana de Farias; SOUZA, Gilson da P. L. Logística 4.0: conceitos e aplicabilidade: uma pesquisa-ação em uma empresa de tecnologia para o mercado automobilístico. Caderno PAIC, v. 17, n. 1, p. 237-261, 2016.

GIL, Antônio Carlos. Como elaborar projetos de pesquisa. 3. ed. São Paulo: Atlas, 1991. 159 p.

HERMANN, Mario; PENTEK, Tobias; OTTO, Boris. Design principles for industrie 4.0 scenarios. In.: 2016 49th Hawaii international conference on system sciences (HICSS). IEEE, 2016. p. 39283937. Disponível em: https://ieeexplore.ieee.org/abstract/document/7427673. Acesso em: 01 maio 2020.

OLIVEIRA JUNIOR, Libório de. Modelo de maturidade para a indústria 4.0 para PME's brasileiras: um estudo de caso em uma indústria de ração animal. 2019. Dissertação (Mestrado) Universidade Tecnológica Federal do Paraná. Programa de Pós-Graduação em Engenharia de Produção e Sistemas, Pato Branco, PR, 2019. Disponível em: http://repositorio.utfpr.edu.br/. Acesso em 15 jul. 2020. 


\title{
RECIMA21 - REVISTA CIENTÍFICA MULTIDISCIPLINAR
}

\author{
MODELO DE AVALIAC̄ÃO DE MATURIDADE DA INDÚSTRIA 4.0 - ESTUDO DE CASO \\ EM UM CENTRO DE DISTRIBUIČ̃̃O DE MEDICAMENTOS NA BAIXADA FLUMINENSE/RJ \\ Jorge Luiz Machado, Mariana Gonçalves de Carvalho Wolff, Ariele Silva Moreira Rodrigues, \\ Denise Carvalho Takenaka, Marcos Azevedo Benac
}

MARQUES, Joana Brás Varanda, FREITAS, Denise de. Método Delphi: caracterização e potencialidades na pesquisa em Educação. Pro-Posições, Campinas, v. 29, n. 2, 2018. Disponível em: www.scielo.br. Acesso em: 10 jul. 2020.

MARTINS, Mozart Santos. Inovações tecnológicas da indústria 4.0: aplicações e implicações para a siderurgia brasileira. 2019. Dissertação (Mestrado) - Instituto de Economia e Relações Internacionais, Universidade Federal de Uberlândia, Uberlândia, 2019. Disponível em: http://repositorio.ufu.brl. Acesso em 20 jul. 2020.

MENDONÇA, Claudio Márcio Campos. M. C.; ANDRADE, Antônio Manuel Valente de; SOUSA NETO, Manoel Veras de. Uso da loT, big data e inteligência artificial nas capacidades dinâmicas. Revista Pensamento contemporâneo em Administração, Rio de Janeiro, v. 12, n. 1, p. 131-151, jan./mar. 2018. Disponível em: https://periodicos.uff.br/. Acesso em: 18 maio 2020.

MORAIS, Marcos de Oliveira; MOURA, IIma de; DENANI, André Luís. A integração entre conhecimento, inovação e indústria 4.0 nas organizações. Brazilian Journal of Development, Curitiba, v. 4, n. 7, p. 3716-3731, Nov. 2018. Disponível em: www.brazilianjournals.com. Acesso em: 07 maio 2020.

MOREIRA, Leandro Domingos. Indústria 4.0: estudo da cadeia produtiva da madeira no Paraná. 2017. (Monografia) - Universidade Tecnológica Federal do Paraná Departamento Acadêmico de Eletrônica - Curitiba - PR, 2017. Disponível em: http://repositorio.roca.utfpr.edu.br/. Acesso em: 15 jul. 2020.

NASCIMENTO, Carlos Alberto, et al. Inovação nos negócios por meio da análise de big data. International Journal of Professional Business Review, São Paulo, v. 3, n. 1, p. 01-16, Jan/Jun. 2018. Disponível em: http://dx.doi.org/10.26668/businessreview/2018.v3i1.65. Acesso em: 20 jul. 2020.

RIBEIRO, João Pedro Vianna. Proposta de adaptação de modelo de maturidade para avaliação de indústrias brasileiras em indústria 4.0. 2018. Projeto de Graduação (Engenharia de Produção) - Universidade de Brasília (UNB), Brasília, 2018. Disponível em: https://bdm.unb.br/. Acesso em: 20 abr. 2020.

SANTOS, Beatrice Paiva; ALBERTO, Agostinho; LIMA, Tânia Daniela Felgueiras Miranda. et al. Indústria 4.0: desafios e oportunidades. Revista Produção e Desenvolvimento, Rio de Janeiro, v.4, n. 1 , p.111-124, 2018. Disponível em: https://revistas.cefetri.br/index.php/producaoedesenvolvimento/article/view/e316/193. Acesso em: 20 jul. 2020.

SANTOS, Reginaldo Carreiro. Proposta de modelo de avaliação de maturidade da Indústria 4.0. 2016. Dissertação (Mestrado) - Instituto Superior de Engenharia de Coimbra, Coimbra - Portugal, 2016. Disponível em: http://comum.rcaap.pt/. Acesso em 07 maio 2020.

SANTOS, Taina Alves dos. As competências individuais em projetos da Indústria 4.0. 2018. Dissertação (Mestrado) - Universidade Nove de Julho - UNINOVE, São Paulo, 2018, p. 115. Disponível em: repositório.uninove.br. Acesso em 01 maio 2020.

SCHUH, Günther. et al. Industrie 4.0 Maturity Index. Managing the Digital Transformation of Companies. Munich: Herbert Utz, 2017. Disponível em: https://en.acatech.de/wpcontent/uploads/sites/6/2020/04/aca STU MatInd 2020 en Web-1.pdf. Acesso em: 01 maio 2020.

SCHUMACHER, Andreasn; EROL, Selimn; SIHN, Wilfried. A maturity model for assessing Industry 4.0 Readiness and maturity of manufacturing enterprises. Procedia CIRP, v. 52, p.161-166, 2016. Disponível em: https://www.sciencedirect.com/science/article/pii/S2212827116307909. Acesso em: 01 maio 2020. 


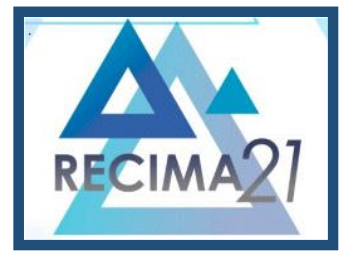

\section{RECIMA21 - REVISTA CIENTÍFICA MULTIDISCIPLINAR}

MODELO DE AVALIACÃO DE MATURIDADE DA INDÚSTRIA 4.0 - ESTUDO DE CASO EM UM CENTRO DE DISTRIBUIÇÃO DE MEDICAMENTOS NA BAIXADA FLUMINENSE/RJ

Jorge Luiz Machado, Mariana Gonçalves de Carvalho Wolff, Ariele Silva Moreira Rodrigues, Denise Carvalho Takenaka, Marcos Azevedo Benac

SILVA, Marcio Roque dos Santos da. Tecnologias digitais associadas à indústria 4.0 na formação profissional: um estudo de caso no CCET/UFS. 2018. (Monografia) - Departamento de Administração do Centro de Ciências Sociais Aplicadas, Universidade Federal de Sergipe, São Cristóvão, 2018. Disponível em: https://periodicos.feevale.br/seer/. Acesso em 20 jul. 2020.

SILVA, Marcus Vinicius Gonçalves da; ROCHA, Clarissa Figueredo. Avaliação do Nível de Maturidade da Indústria 4.0: O Caso de uma Empresa Estratégica de Defesa. Future Studies Research Journal: Trends and Strategies [FSRJ], São Paulo, v. 12, n. 1, p. 31-59, jan./abr. 2020. Disponível em: www.researchgate.net. Acesso: em 01 maio 2020.

SILVA, Mateus Aparecido Camargo da. Potenciais ganhos de produtividade com a Indústria 4.0. 2017. Trabalho de Conclusão de Curso (Graduação) - Curso de Engenharia Mecânica, Universidade Tecnológica Federal do Paraná, Cornélio Procópio, 2017. Disponível em: www.periodicos.capes.gov.br. Acesso em 02 maio 2020.

SILVA, Guilherme Policarpio da. Identificação dos impactos da indústria 4.0 nas organizações: uma revisão sistemática de literatura. 2018. Trabalho de Conclusão de Curso. Universidade Tecnológica Federal do Paraná.

VENÂNCIO, André Luiz A. C.; BREZINSKI, Guilherme Louro. Sistema de avaliação de maturidade industrial baseando-se nos conceitos da indústria 4.0. Trabalho de Conclusão de Curso (Graduação) - Universidade Tecnológica Federal do Paraná Departamento Acadêmico de Eletrotécnica, Curitiba-PR, 2017. Disponível em: http://docplayer.com.br/. Acesso em 15 jul. 2020.

VENTURELLI, Márcio. Tecnologias Habilitadoras. Vídeo (31min), maio 2019. Disponível em: https://marcioventurelli.com/. Acesso em 01 maio 2020.

ZIQUINATO, Guilherme Aparecido Fernandes; SILVA, Luiz Fernando da; DELFORNO, Renato Ferreira. Logística enxuta e endereçamento: redução de custos de armazenagem e movimentação. (Monografia) Curso de Engenharia de Produção - Universidade São Francisco, Itatiba, 2016. 